Review Article

\title{
Complementary and Alternative Medicine for the Treatment of Abnormal Endometrial Conditions in Women with PCOS: A Systematic Review and Meta-Analysis of Randomized Controlled Trials
}

\author{
Jiayu Hu $\mathbb{D}^{1},{ }^{1}$ Wenhua Shi $\mathbb{D}^{2},{ }^{2}$ Jiayue Xu $\mathbb{D}^{1},{ }^{1}$ Shaoxuan Liu $\mathbb{D}^{1},{ }^{1}$ Siya Hu ${ }^{\mathbb{D}},{ }^{1}$ Wenjing Fu $\mathbb{D}^{1}$, \\ Jing Wang $\left(\mathbb{D},{ }^{3}\right.$ and Fengjuan Han $\mathbb{D}^{4}$ \\ ${ }^{1}$ Heilongjiang University of Chinese Medicine, Harbin 150040, China \\ ${ }^{2}$ Fourth Affiliated Hospital of Harbin Medical University, Harbin 150040, China \\ ${ }^{3}$ People's Hospital of Langfang City, Langfang 65000, China \\ ${ }^{4}$ First Affiliated Hospital of Heilongjiang University of Chinese Medicine, Harbin 150040, China
}

Correspondence should be addressed to Jing Wang; 1733142462@qq.com and Fengjuan Han; hanfengjuan2004@163.com

Received 5 January 2021; Revised 19 March 2021; Accepted 25 March 2021; Published 30 April 2021

Academic Editor: Linus R. Shao

Copyright ( $\odot 2021$ Jiayu Hu et al. This is an open access article distributed under the Creative Commons Attribution License, which permits unrestricted use, distribution, and reproduction in any medium, provided the original work is properly cited.

Background. Endometrial lesions in patients with polycystic ovary syndrome (PCOS) exhibit complex pathological features, and these patients are at risk of both short-term and long-term complications. Complementary and alternative medicine (CAM), which is gradually becoming more accepted and is believed to be clinically effective, claims to be promising for treating PCOS, and thus its effect on the abnormal endometrium of PCOS patients should be assessed. The present meta-analysis sought to evaluate the efficacy and safety of CAM in treating endometrial lesions in patients with PCOS. Methods. Randomized trials on CAM were identified in four Chinese and seven English-language databases from their establishment to January 2020. The present study included patients diagnosed with PCOS and abnormal endometrial conditions who underwent CAM therapy independently or in combination with traditional western medicine. Data were extracted, and the Cochrane "risk of bias" tool was used to assess methodological quality. Effects were expressed as the relative risk (RR) or mean difference (MD/SMD) with $95 \%$ confidence interval (CI) as calculated with Rev Man 5.3. Results. A total of 13 randomized controlled trials were included, involving 1,297 PCOS patients treated for endometrial abnormalities. Methodological quality was generally unclear or had a low risk of bias. The trials tested four different types of CAM therapies (i.e., traditional Chinese medicine treatment, acupuncture treatment, traditional Chinese medicine in combination with western medicine treatment, and acupuncture in combination with western medicine treatment). CAM treatment could significantly reduce the endometrial thickness in PCOS patients compared to western medicine alone (SMD $-0.88,95 \%$ CI $\left.[-0.12,-0.57] ; I^{2}=64 \%\right)$. Compared with clomiphene treatment for the induction of ovulation, CAM treatment showed a clear improvement in endometrial thickness during ovulation (SMD 2.03, 95\% CI [1.64, 2.02]; $I^{2}=48 \%$ ). Moreover, CAM was more effective than western medicine alone in reducing the endometrial spiral artery pulsatility index. No significant difference was seen between CAM and traditional treatment when these were used to improve traditional Chinese medicine syndrome scores. Acupuncture alone or traditional Chinese medicines (taken orally) in combination with western medicine significantly increased the pregnancy rate of PCOS patients (RR 1.59, 95\% CI $[1.30,1.93] ; I^{2}=51 \%, P<0.00001$ ), and CAM was more effective than western medicine alone for improving hormone levels. No serious adverse events were reported in 11 of the 13 trials. Conclusions. CAM may effectively ameliorate the endometrial condition of PCOS patients, and it can regulate the level of hormone secretion to increase the ovulation rate and the pregnancy rate. 


\section{Introduction}

Polycystic ovary syndrome (PCOS) is a gynecological endocrine disease that is characterized by oligo-ovulation, hyperandrogenemia, and hyperinsulinemia. The prevalence of PCOS has been estimated to be $6-12 \%$ in women of childbearing age worldwide [1-3], and the rate in China is about 5.6\% [4]. PCOS patients are at increased risk for various complications (e.g., insulin resistance and endometrial abnormalities) along with the typical clinical characteristics of polycystic ovaries, sparse ovulation, and abnormal hormone levels. Changes in the endometrium are among the most common clinical manifestations and complications in PCOS patients. The endometrium of PCOS patients tends to exhibit pathological hyperplasia (e.g., simple hyperplasia, complex hyperplasia, or atypical hyperplasia) [5] due to the long-term exposure to estrogen and the lack of regular progesterone antagonism. As indicated from a previous meta-analysis, PCOS patients are at a higher risk of endometrial cancer, suggesting that long-term pathological endometrial hyperplasia contributes strongly to the development of endometrial cancer [6]. Likewise, PCOS patients suffering from insulin resistance are likely to experience accelerated proliferation of endometrial cells as well as an increased likelihood of long-term complications. In contrast, PCOS patients with infertility suffer from relatively poor endometrial conditions, thereby significantly reducing their pregnancy rate and live birth rate and adversely affecting their health status and their personal family life. When providing treatments for ovulation induction, variations in uterine receptivity have a significant effect on pregnancy outcome [7]. However, there are some indications that modern medical treatments might adversely affect endometrial receptivity in infertile PCOS patients [8]. CAM, which is commonly used to treat PCOS, has been shown to have a positive effect on controlling patients' weight, body mass index, sleep quality, ovulation rate, quality of life, etc. [9-12]. However, no systematic review or research has been conducted on the effects of CAM on the endometrium in PCOS patients, and the endometrium has rarely been discussed as the main outcome index. Therefore, this study undertook a comprehensive literature search on CAM for endometrial intervention in PCOS patients and carried out a systematic review and meta-analysis to supplement the existing evidence in order to determine the contribution of CAM for endometrium abnormalities in PCOS patients and to underpin the clinical treatment of long-term endometrial complications and infertility. Furthermore, only randomized controlled trials (RCTs) were included in the systematic review.

Because PCOS exhibits obvious heterogeneity and because diagnostic standards vary in different regions, this study only included cases that were diagnosed according to the joint criteria of the European Society of Human Reproduction and Embryology (ESHRE) and the American Society of Reproductive Medicine (ASRM) established in Rotterdam in 2003 [13] or according to the Chinese Health Industry Standard WS330-2011: Diagnosis of Polycystic Ovary Syndrome issued by the Chinese Ministry of Health in
2011 [14]. The types of intervention consisted of CAM methods used alone or in combination with traditional western medicine therapy for PCOS.

The concept of CAM has numerous meanings. This study attempted to include as many types of CAM therapies as possible in the literature retrieval in order to avoid any bias in the results due to the omission of therapies. According to the existing research, this study included the following treatment methods within the scope of CAM to treat PCOS: traditional Chinese medicine (TCM), acupuncture, moxibustion, diet suggestions/restrictions, psychological counseling, exercise therapy, and other known CAM methods for treating PCOS [15-19].

\section{Method}

2.1. Search Strategy. A systematic literature search was conducted in four Chinese databases (CNKI, WANFANG, VIP, and SINOMED) and seven English databases (PubMed, EMBASE, Web of Science, ProQuest Research Library, Medline, Elsevier/ScienceDirect, and The Cochrane Library) from their time of establishment to January 2020. In addition, gray literature was searched (e.g., meeting minutes). We searched using different combinations of key words, including "polycystic ovary syndrome", "endometrium", "complementary and alternative medicine", "traditional Chinese medicine", "acupuncture", "moxibustion", "exercise therapy", and "diet intervention".

2.1.1. Literature Selection and Data Extraction. Two authors (J. Y. Xu and W. J. Fu) independently checked the full text to identify qualified RCTs, and four authors (J. Y. Hu, J. Y. Xu, S. X. Liu, and S. Y. Hu) collaborated with each other to extract data from the included articles according to the predesigned data table. Any conflicts were resolved through discussions with the third author (F. J. Han). The following items were extracted: year of publication, type of study, funding, inclusion/exclusion criteria, diagnostic criteria, research methods, demographic characteristics of the participants, details of the intervention and control, methods of outcome measurement, and adverse events and outcomes.

2.1.2. Quality Assessment. Two authors (J. Y. Hu and J. Y. $\mathrm{Xu}$ ) used the "risk of bias tool" [20] to assess the methodological quality of the included RCTs. The RCTs were judged as "low risk", "high risk", or "uncertain risk" based on risks involving random sequence generation, assignment concealment, blindness of participants and personnel, blindness of the outcome assessment, incomplete data, selective reporting, and other biases (e.g., drug company funding). Any conflicts were resolved through discussions with the third author (F. J. Han).

2.2. Data Analysis. This study used the Rev Man 5.3 software for all data analysis. For continuous data, the mean difference (MD/SMD) and 95\% confidence interval (CI) were calculated, while for binary data the relative risk (RR) and 
95\% CI were calculated. If similar study designs, participants, interventions, controls, and outcome indicators were found, then those trials were included in a meta-analysis. Mega data were generated by descriptive counting. Other data not suitable for combination analysis were qualitatively synthesized. In compliance with the recommendations of the Cochrane Handbook for Systematic Reviews of Interventions (Higgins 2011), we used the $\mathrm{I}^{2}$ test for statistical heterogeneity. If $I^{2}$ is greater than $50 \%$, this indicates that there may be substantial heterogeneity [20], so we used the random effects model for data pooling with significant heterogeneity $\left(I^{2} \geq 50 \%\right)$; otherwise, we used the fixed effect model. If data were available, a subgroup analysis was conducted on the subcategories of CAM and a sensitivity analysis was conducted to explore the impact of the type of RCT (parallel or cross randomized) and the quality of the trial (high or low). If more than ten trials were included in the meta-analysis, a funnel chart was generated to explore possible publication bias.

2.3. Outcomes. The main analysis included the treatment outcome indicators as measured by one or more of the following items: endometrial thickness (ovulation or luteal metaphase); endometrial type and ovulation rate detected by ultrasound; the levels of sex hormones (mainly follicle stimulating hormone (FSH), luteinizing hormone ( $\mathrm{LH})$, and estradiol $\left(E_{2}\right)$ ) as measured by chemiluminescence immunoassay; the number of pregnancies (or pregnancy rate) as measured by the level of human chorionic gonadotropin (HCG) and by ultrasound; and the type, number, and probability of adverse reactions. The secondary results included the endometrial spiral artery pulsatility index (PI) and endometrial spiral artery resistance index (RI) of the spiral uterine artery as detected by ultrasound, the cervical mucus score as measured by the Insler cervical scoring method, the early spontaneous abortion rate, the proportion of participants with $\geq 50 \%$ improvement in symptoms and signs according to the assessment of clinicians, and the number or probability of patients with a TCM syndrome differentiation type showing improvement in the TCM syndrome score.

\section{Results}

A total of 1,633 articles were retrieved, including 1,001 in Chinese and 632 in English. After the titles and abstracts were browsed, 1,184 cited trials were excluded due to involving in vitro research, being a dissertation or being nonRCT research, and 352 were duplicates. Among the 97 eligible studies, 34 were excluded for having unreasonable random distribution methods, 12 for having incomplete data or missing outcome indicators, 28 for not mentioning the diagnostic criteria or the inclusion criteria, and 10 for lacking clear methods or criteria for outcome indicators. Finally, 13 trials [21-33] including 1,297 PCOS patients were included in the present review (Figure 1). Twelve of the included trials were in Chinese and one was in English, and all of the studies included patients from mainland China and were carried out by researchers and scholars in mainland China.

The characteristics of the 13 RCTs are shown in Table 1. The sample sizes of the included studies ranged from 56 to 198 participants who ranged in age from 17 to 38 years. In all 13 trials, clinical western medicine treatment for PCOS (e.g., clomiphene and metformin) was used as the western medicine control group, and these included both single drug treatments and multiple drug combinations. In three trials $[24,26,33]$, the patients were treated by using CAM alone, with one study using acupuncture alone [33] and two using TCM alone $[24,26]$. The remaining 10 trials [21-23, 25, 27-33] used CAM in combination with western medicine. The western medicine control group consisted of clomiphene, metformin, Diane-35, or letrozole alone as well as their combinations with human menopausal gonadotropin (HMG) and HCG.

3.1. Bias Risk in the Trials. Three trials $[26,28,31]$ were considered to have "unclear" selection bias risk because they only mentioned "random" without describing any specific method of randomization, while the remaining ten trials $[21-25,27,29,30,32,33]$ were considered to have a "low" selection bias risk because the methods for generating the random sequence were mentioned (random number table). In one trial [25] considering a "high" reporting bias risk, a case was withdrawn, and this might have led to incomplete follow-up data. The other 12 trials that did not have any case withdrawals included follow-up information [21-24, 26-33] and were considered to have "low" reporting bias risk. Four trials $[25,26,29,32]$ did not report specific details of sample size calculation and were defined as "unclear" risk of other bias (Figures 2 and 3).

3.1.1. Endometrial Thickness. Four studies comparing CAM with western medicine treatment and involving 511 patients $[21,26,27,32]$ showed that CAM treatment can significantly reduce the endometrial thickness resulting from abnormal hyperplasia in PCOS patients (SMD $-0.88,95 \%$ CI $[-0.12$, -0.57 ]; $I^{2}=64 \%$ ) (Figure 4). A comprehensive analysis was performed on the nine articles studying endometrial thickness after CAM alone or in combination with western medicine treatment in PCOS patients with infertility [22-25, 28-31,33], and the results were found to be highly heterogeneous (SMD 1.23, 95\% CI $[0.50,1.96] ; I^{2}=95 \%$ ) (Figure 5(a)). A subgroup analysis was conducted, suggesting that CAM treatment compared with clomiphene therapy for ovulation stimulation significantly increased the endometrial thickness during ovulation (SMD 2.03, 95\% CI $[1.64,2.02] ; I^{2}=48 \%$ ) (Figure $\left.5(\mathrm{~b})\right)[24,33]$.

3.1.2. Type of Endometrium. In three articles involving 358 patients [23, 25, 33], CAM alone (acupuncture) and CAM (oral TCM) in combination with western medicine effectively increased the number of PCOS patients with type A endometrium compared with clomiphene (RR 1.44, 95\% CI $[1.22,1.69] ; I^{2}=0 \%, P<0.0001$ ) (Figure 6). In two articles 


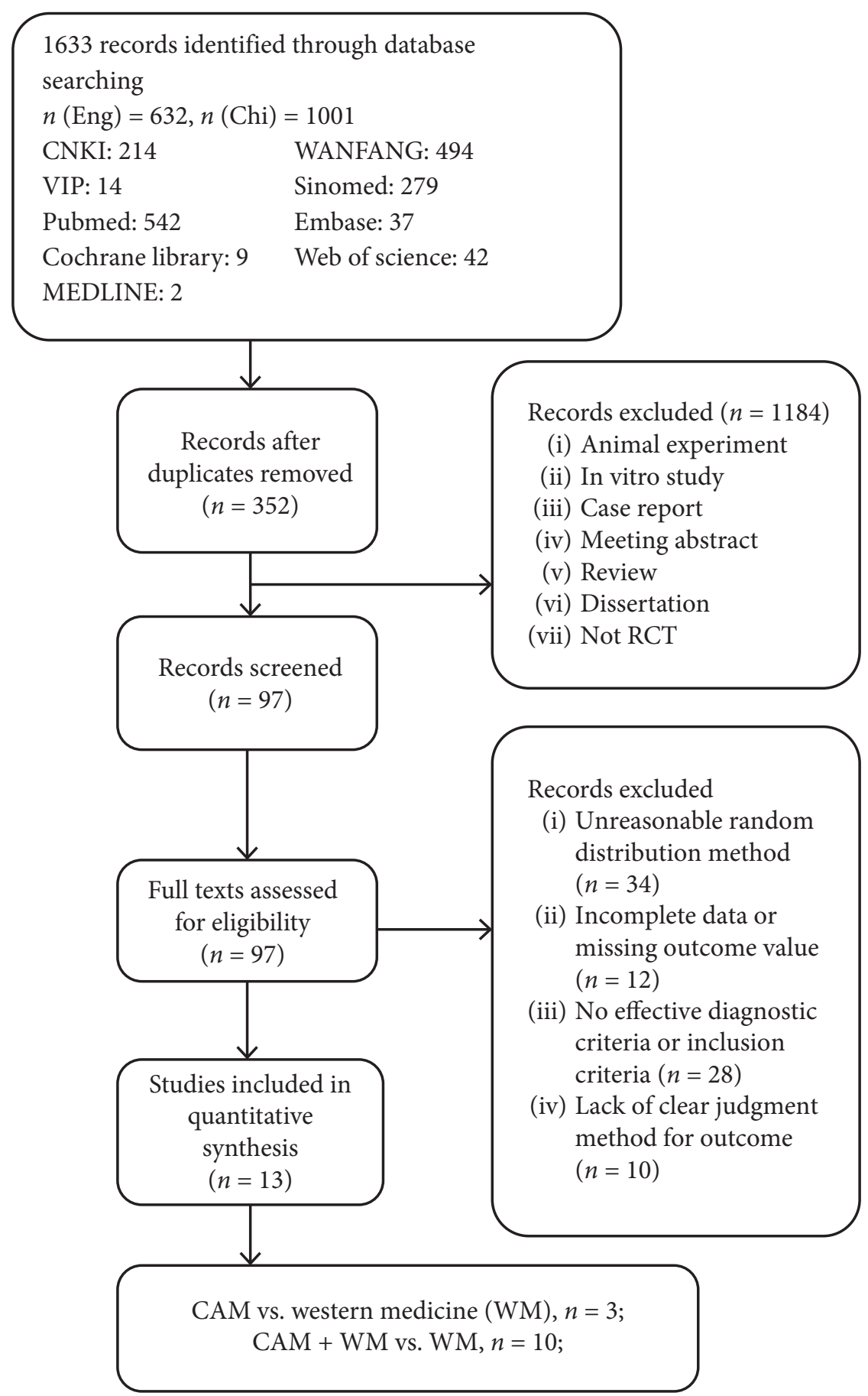

FIGURE 1: Flow diagram of study selection and different subgroup interventions included in this review.

$[23,33]$, both acupuncture alone and oral TCM combined with clomiphene significantly downregulated the number of cases of type $\mathrm{B}$ and type $\mathrm{C}$ endometrium in PCOS patients (RR $0.27,95 \%$ CI $[0.10,0.73] ; I^{2}=60 \%, P=0.01$ ) (Figure 7).

3.1.3. PI and RI. In two trials involving ovulation stimulation in 158 PCOS patients $[29,31]$, oral TCM in combination with western medicine could effectively reduce the PI compared with western medicine alone (MD $-0.27,95 \% \mathrm{CI}$ $[-0.38,-0.16] ; \mathrm{I}^{2}=10 \%, P<0.00001$ ) (Figure 8) but had no significant effect on RI (MD $-0.11,95 \%$ CI $[-0.22,0.00]$; $I^{2}=0 \%, P=0.05$ ) (Figure 9).

3.1.4. Hormone Levels. Seven trials involving 693 patients $[21,23,24,27,30,32,33]$ showed that CAM alone or CAM in combination with western medicine clearly reduced FSH levels compared with clomiphene and Diane-35 (SMD -0.18, 95\% CI $[-0.13,-0.33] ; I^{2}=46 \%$ ) (Figure 10). The LH levels in patients treated with TCM or acupuncture in combination with western medicine were not statistically different 
TABLE 1: Characteristics of included randomized clinical trials on CAM therapies for PCOS abnormal endometrial conditions.

\begin{tabular}{|c|c|c|c|c|c|}
\hline Study ID & $\begin{array}{c}\text { Sample } \\
\text { size }\end{array}$ & Age & Comparisons & Outcome & Follow-up \\
\hline \multicolumn{6}{|c|}{ CAM vs. WM, 3 studies } \\
\hline $\begin{array}{l}\text { Fang et al. } \\
{[24]}\end{array}$ & $\begin{aligned} \mathrm{T}: & 28^{\circ} \mathrm{C}: \\
& 28\end{aligned}$ & $\begin{array}{l}\mathrm{T}: 27.54 \pm 3.65 \\
\text { years } \\
\mathrm{C:} 28.24 \pm 4.36 \\
\text { years }\end{array}$ & Chinese medicine prescription vs. clomiphene $(3 \mathrm{~m})$ & (1) (2) (3) (8) & NR \\
\hline $\operatorname{Li}[26]$ & $\begin{aligned} \mathrm{T}: & 74^{\circ} \mathrm{C}: \\
& 74\end{aligned}$ & $\begin{array}{l}\mathrm{T}: 27.8 \pm 3.50 \\
\text { years } \\
\mathrm{C:} 228.0 \pm 3.50 \\
\text { years }\end{array}$ & $\begin{array}{c}\text { Chinese medicine prescription + progesterone capsule (under } \\
\text { certain conditions) vs. HMG + HCG + progesterone capsule } \\
\text { (under certain conditions) }(3-6 \mathrm{~m})\end{array}$ & (1) (3) (6) (9) & NR \\
\hline Zhuo [33] & $\begin{array}{c}\mathrm{T}: 50^{\circ} \mathrm{C}: \\
50\end{array}$ & $\begin{array}{l}\text { T: } 29 \pm 5 \text { years } \\
\text { C: } 28 \pm 5 \text { years }\end{array}$ & Acupuncture vs. clomiphene $(3 \mathrm{~m})$ & (1) (2) (4) (5) (11) (12) & NR \\
\hline \multicolumn{6}{|c|}{$C A M+W M$ vs. WM, 10 studies } \\
\hline $\begin{array}{l}\text { Chen et al. } \\
{[22]}\end{array}$ & $\begin{aligned} \mathrm{T}: & 30^{\circ} \mathrm{C}: \\
& 30\end{aligned}$ & $\begin{array}{l}\text { T: } 28.63 \pm 0.73 \\
\text { years } \\
\text { C: } 30.13 \pm 0.75 \\
\text { years }\end{array}$ & $\begin{array}{l}\text { Ding Kundan + clomiphene }+ \text { HMG }+ \text { dydrogesterone (under } \\
\text { certain conditions) vs. clomiphene }+ \text { HMG }+ \text { dydrogesterone } \\
\text { (under certain conditions) }(1 \mathrm{~m})\end{array}$ & (1) (3) (4) (5) (10) & $1 \mathrm{~m}$ \\
\hline Chen $[21]$ & $\begin{aligned} \mathrm{T}: & 32^{\circ} \mathrm{C}: \\
& 31\end{aligned}$ & $\begin{array}{l}\mathrm{T}: 28.63 \pm 0.73 \\
\text { years } \\
\mathrm{C:} 30.13 \pm 0.75 \\
\text { years }\end{array}$ & $\begin{array}{l}\text { Yougui Pill (adjusted according to conditions) + Diane-35 vs. } \\
\text { Diane-35 (3 m) }\end{array}$ & (1) (2) (5) (7) & $6 \mathrm{~m}$ \\
\hline $\mathrm{Du}[23]$ & $\begin{aligned} \mathrm{T}: & 57^{\circ} \mathrm{C}: \\
& 57\end{aligned}$ & $\begin{array}{l}\text { T: } 29.4 \pm 5.3 \\
\text { years } \\
\text { C: } 28.6 \pm 5.7 \\
\text { years }\end{array}$ & $\begin{array}{l}\text { Chinese medicine prescription + ethinyl estradiol + clomiphene } \\
\text { citrate tablets + HMG vs. ethinyl estradiol + clomiphene citrate } \\
\text { tablets + HMG }(3 \mathrm{~m})\end{array}$ & $\begin{array}{l}\text { (1) (2) (4) (5) (11) } \\
\text { (12) } \\
\text { (13) (16) }\end{array}$ & NR \\
\hline $\begin{array}{l}\text { Hongling and } \\
\text { Limian [25] }\end{array}$ & $\begin{aligned} \mathrm{T}: & 29^{\circ} \mathrm{C}: \\
& 29\end{aligned}$ & $\begin{array}{l}\text { T: } 25.8 \pm 1.8 \\
\text { years } \\
\text { C: } 26.2 \pm 2.4 \\
\text { years }\end{array}$ & $\begin{array}{l}\text { Traditional Chinese medicine + clomiphene citrate } \\
\text { tablets + estradiol valerate + HCG vs. clomiphene citrate } \\
\text { tablets + estradiol valerate + HCG }(3 \mathrm{~m})\end{array}$ & (1) (4) (5) (10) (11) & $3 \mathrm{~m}$ \\
\hline Ma et al. [27] & $\begin{array}{l}\mathrm{T}: 99^{\circ} \mathrm{C}: \\
99\end{array}$ & $\begin{array}{l}\mathrm{T}: 28.7 \pm 5.1 \\
\text { years } \\
\text { C: } 27.4 \pm 14.8 \\
\quad \text { years }\end{array}$ & Chinese medicine prescription + metformin vs. metformin $(3 \mathrm{~m})$ & (1) (2) (3) (6) (7) & NR \\
\hline Ru et al. [28] & $\begin{array}{l}\mathrm{T}: 90^{\circ} \mathrm{C}: \\
\quad 90\end{array}$ & $\begin{array}{l}\text { T: } 26.8 \pm 4.4 \\
\text { years } \\
\text { C: } 26.5 \pm 5.0 \\
\text { years }\end{array}$ & $\begin{array}{l}\text { Chinese medicine prescription }+ \text { clomiphene vs. clomiphene } \\
\qquad(3 \mathrm{~m})\end{array}$ & (1)(2) (3) (4) (5) & NR \\
\hline $\begin{array}{l}\text { Tong et al. } \\
{[29]}\end{array}$ & $\begin{aligned} \mathrm{T}: & 40^{\circ} \mathrm{C}: \\
& 40\end{aligned}$ & $\begin{array}{l}\text { T: } 30.58 \pm 3.82 \\
\text { years } \\
\text { C: } 30.23 \pm 3.53 \\
\text { years } \\
\text { T: } 25.7 \pm 4.0\end{array}$ & $\begin{array}{c}\text { Chinese medicine prescription + clomiphene + HCG (under } \\
\text { certain conditions) + dydrogesterone (under certain conditions) } \\
\text { vs. Clomiphene + HCG (under certain } \\
\text { conditions) + dydrogesterone (under certain conditions) }(3 \mathrm{~m} \text { ) }\end{array}$ & (1) (4) (5) (14) (15) & NR \\
\hline $\begin{array}{l}\mathrm{Xu} \text { and Zho } \\
{[30]}\end{array}$ & $\begin{aligned} \mathrm{T}: & 30^{\circ} \mathrm{C}: \\
& 30\end{aligned}$ & $\begin{array}{c}\text { years } \\
\text { C: } \\
25.8 \pm 4.2 \text { years }\end{array}$ & $\begin{array}{l}\text { Acupuncture + Diane- } 35+\text { HMG }+ \text { HCG vs. Diane- } \\
\qquad 35+\text { HMG }+ \text { HCG }(2 \mathrm{~m})\end{array}$ & $\begin{array}{l}\text { (1) (2) (4) (5) (9)(10) } \\
\text { (14) }\end{array}$ & NR \\
\hline $\begin{array}{l}\text { Zhao et al. } \\
\text { [31] }\end{array}$ & $\begin{aligned} \mathrm{T}: & 38^{\circ} \mathrm{C}: \\
& 40\end{aligned}$ & $\begin{array}{l}\mathrm{T}: 26.21 \pm 3.37 \\
\text { years } \\
\mathrm{C:} 26.30 \pm 3.38 \\
\text { years }\end{array}$ & $\begin{array}{c}\text { Letrozole tablets + Tiao Jing Cu Yun pills + aspirin vs. letrozole } \\
\text { tablets (only } 1 \mathrm{~m} \text { concluded) }\end{array}$ & (1) (4) (15) & NR \\
\hline $\begin{array}{l}\text { Wenqin and } \\
\text { Dianzhou } \\
{[32]}\end{array}$ & $\begin{aligned} \mathrm{T}: & 51^{\circ} \mathrm{C}: \\
& 51\end{aligned}$ & $\begin{array}{l}\text { T: } 28.6 \pm 5.14 \\
\text { years } \\
\text { C: } 29.4 \pm 6.14 \\
\text { years }\end{array}$ & $\begin{array}{l}\text { Tiao jing cu yun pill + clomiphene citrate capsules + HCG vs. } \\
\text { clomiphene + HCG }(3 \mathrm{~m})\end{array}$ & (1) (2) (4) (5) (10) (14) & NR \\
\hline
\end{tabular}




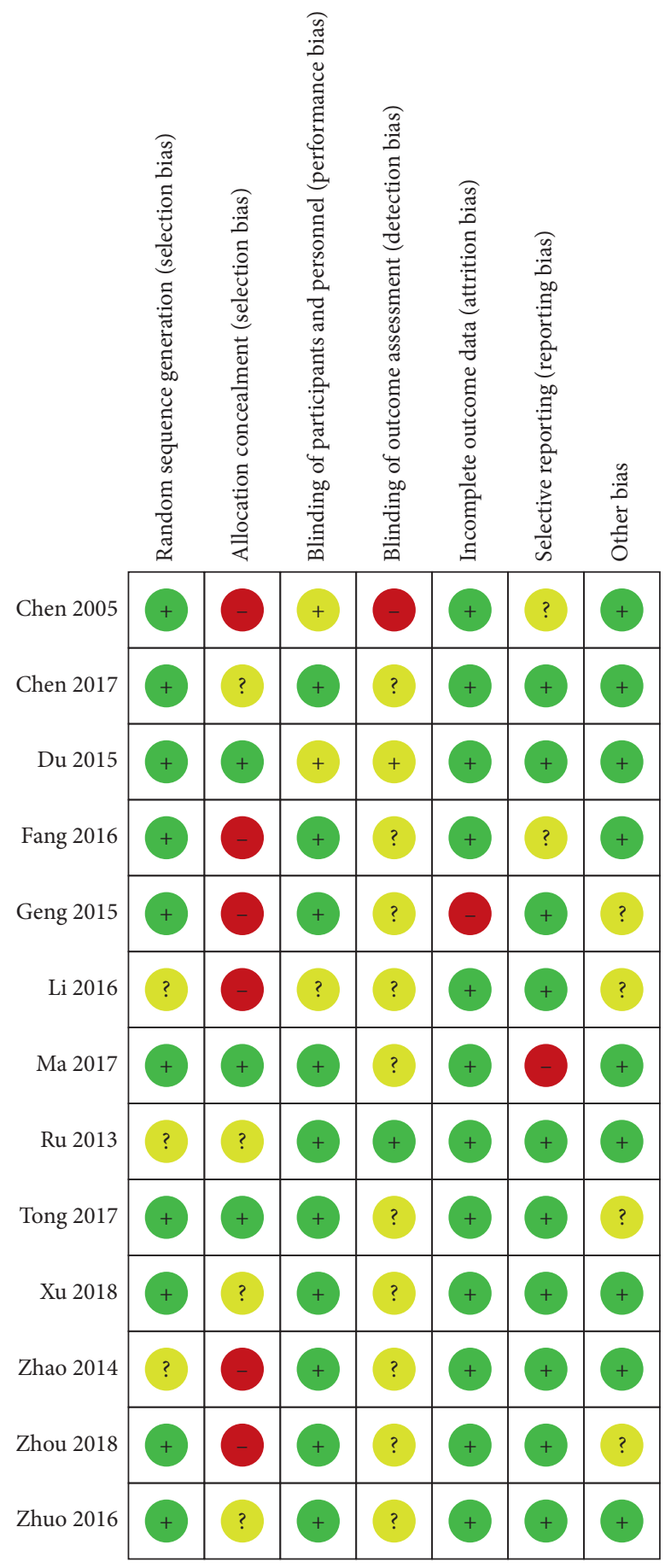

Figure 2: Risk of bias summary.

compared with control patients [24, 33] (Figure 11), while the LH levels in patients treated with acupuncture or TCM in combination with western medicine were significantly improved (SMD $-0.33,95 \%$ CI $[-0.54,-0.12]$; $\left.I^{2}=0 \%, P=0.002\right)$ (Figure 12) $[21,28,33]$. Both CAM alone (acupuncture or oral TCM) and CAM (acupuncture or oral TCM) in combination with western medicine performed better in decreasing testosterone levels compared with clomiphene and Diane-35 (SMD -0.68, 95\% CI $[-1.00,-0.36] ; I^{2}=70 \%, P<0.001$ ) (Figure 13)
[21, 23, 24, 28, 30, 33]. However, western medicine alone and CAM alone or in combination with western medicine did not lead to significant changes in $E_{2}$ levels (SMD 0.31, 95\% CI $[-0.04,-0.65] ; I^{2}=81 \%, P=0.08$ ) $[21,23,24,27,28,30,33]$ (Figure 14).

3.1.5. Number of Dominant Follicles. In two trials involving 208 patients, only oral TCM and acupuncture in combination with western medicine effectively increased the 


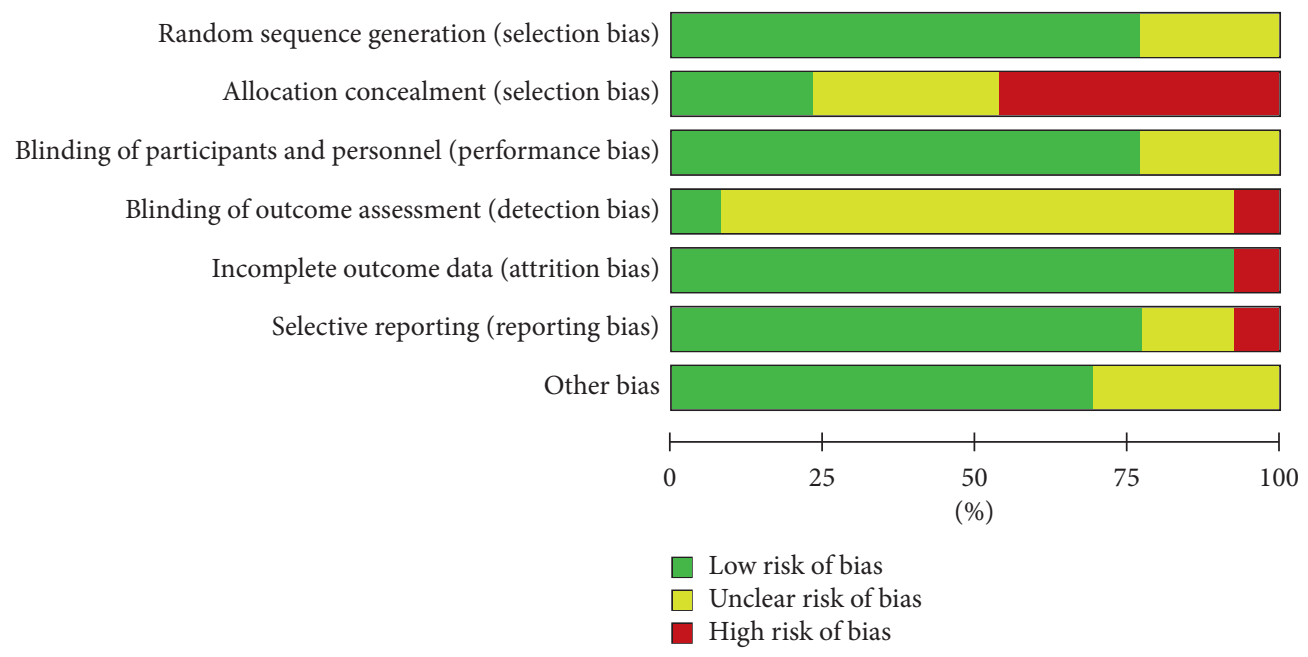

FIgURE 3: Risk of bias graph.

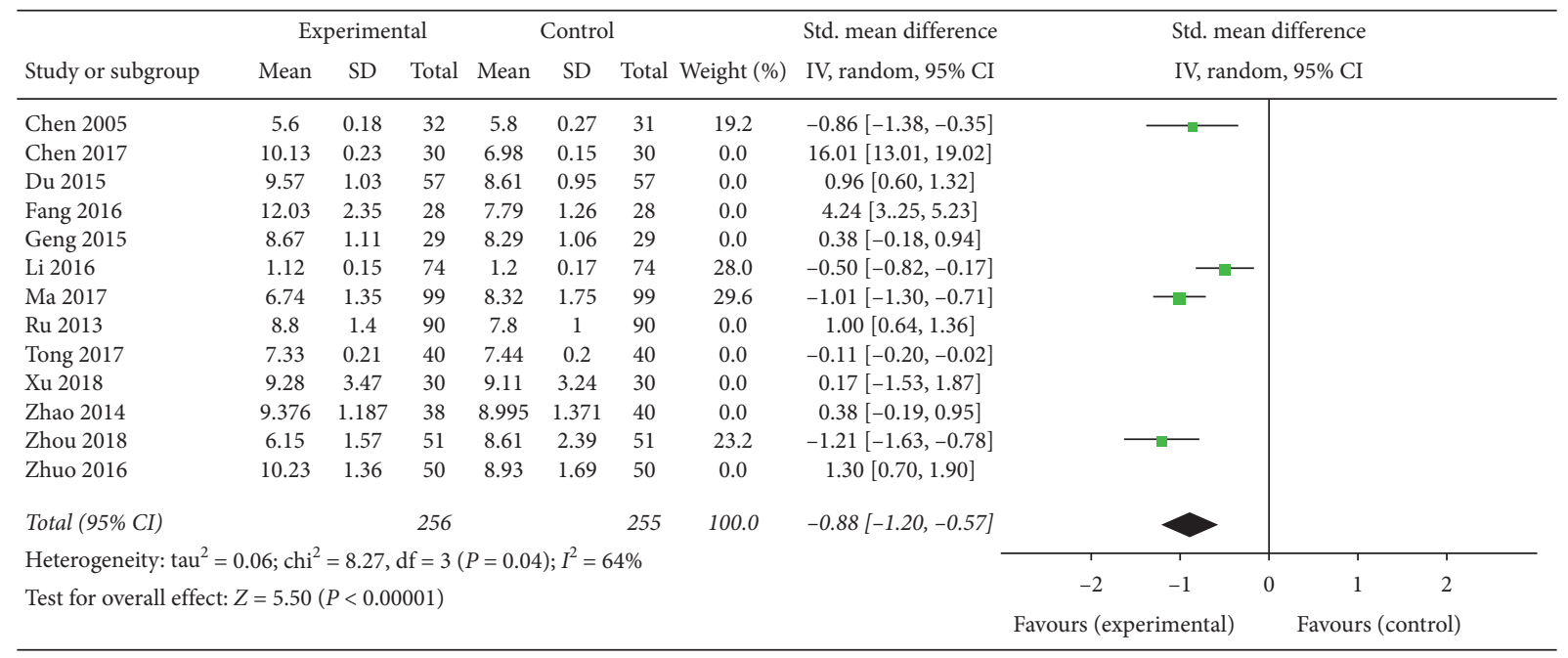

FIGURE 4: Forest plot of reducing endometrial thickness.

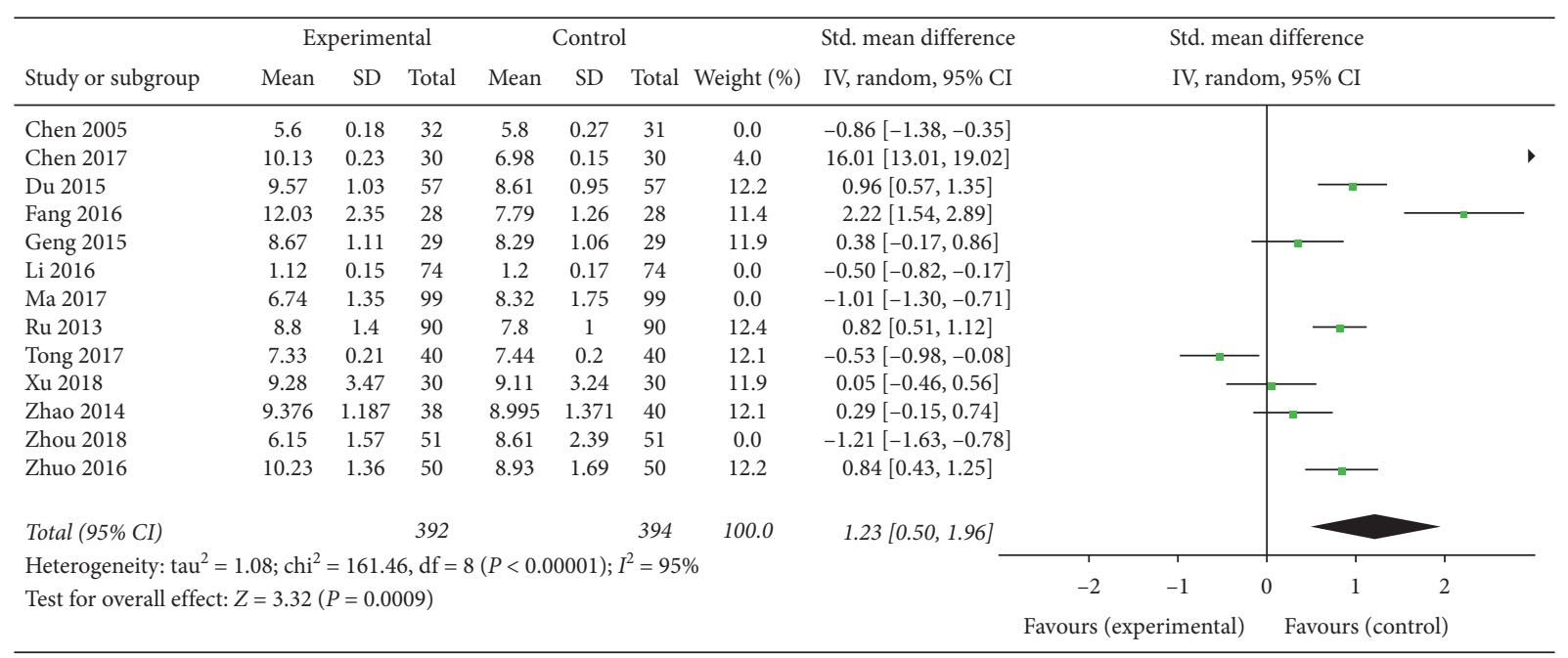

(a)

Figure 5: Continued. 


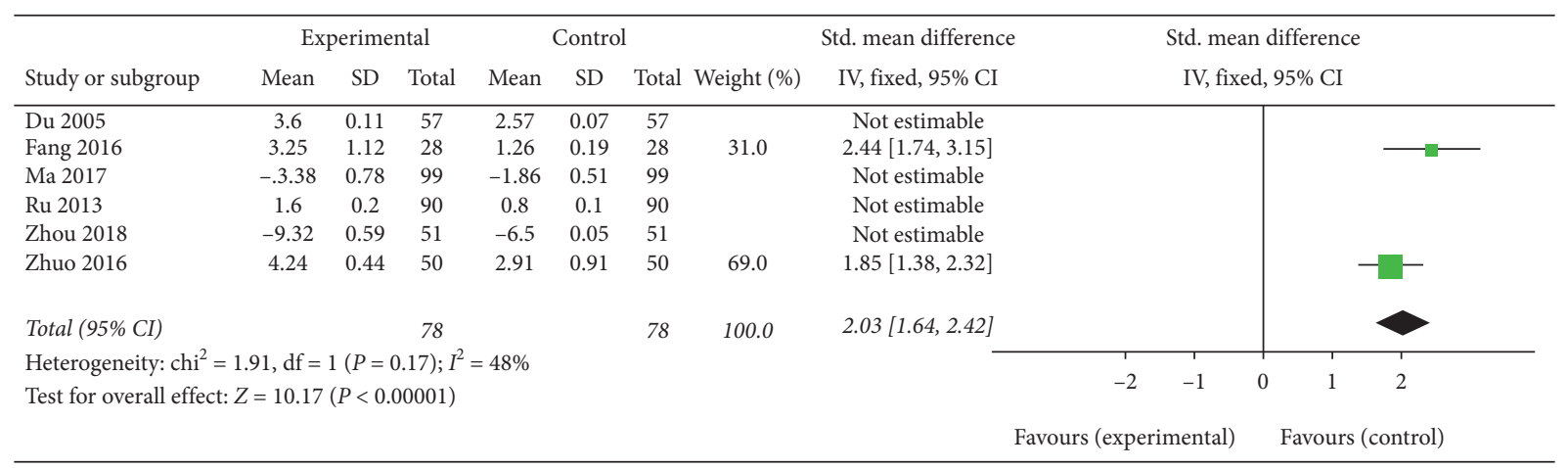

(b)

Figure 5: (a) Forest plot of increasing endometrial thickness. (b) Forest plot of increasing endometrial thickness: CAM vs. clomiphene therapy.

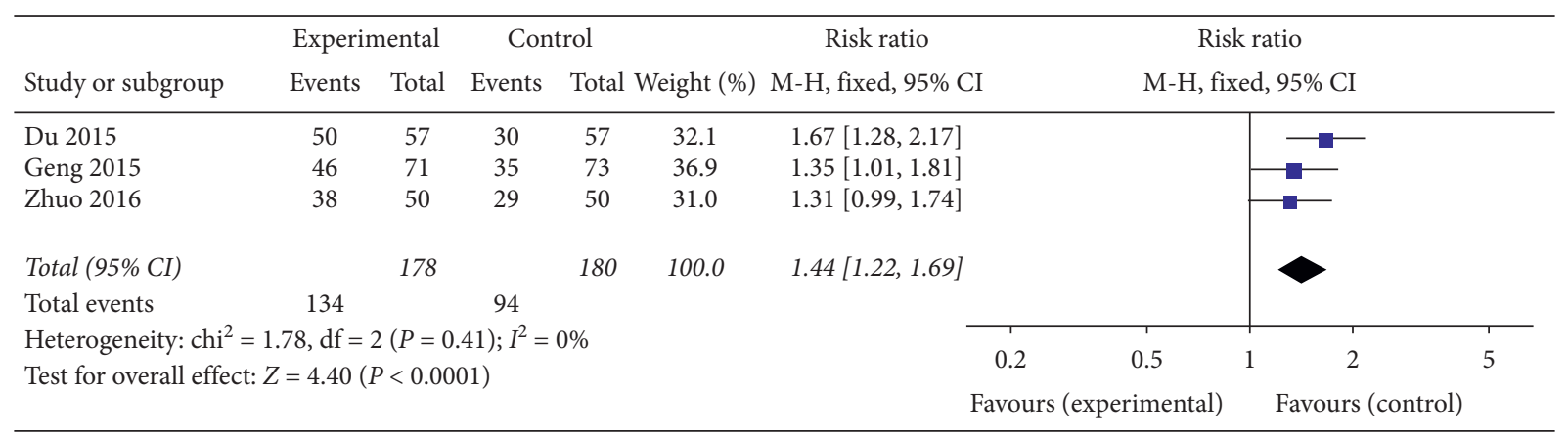

Figure 6: Forest plot of endometrial type A.

\begin{tabular}{|c|c|c|c|c|c|c|c|c|c|c|}
\hline \multirow{4}{*}{$\begin{array}{l}\text { Study or subgroup } \\
\text { Du } 2015 \\
\text { Zhuo } 2016\end{array}$} & \multicolumn{2}{|c|}{ Experimental } & \multicolumn{2}{|c|}{ Control } & & \multirow{2}{*}{\multicolumn{2}{|c|}{$\begin{array}{l}\text { Odds ratio } \\
\mathrm{M}-\mathrm{H} \text {, random, } 95 \% \mathrm{CI}\end{array}$}} & \multirow{2}{*}{\multicolumn{2}{|c|}{$\begin{array}{c}\text { Odds ratio } \\
\mathrm{M}-\mathrm{H} \text {, random, } 95 \% \mathrm{CI}\end{array}$}} & \\
\hline & \multirow{2}{*}{$\frac{\text { Events }}{7}$} & \multirow{2}{*}{$\begin{array}{c}\text { Total } \\
57\end{array}$} & \multirow{2}{*}{$\frac{\text { Events }}{27}$} & \multicolumn{2}{|c|}{ Total Weight (\%) } & & & & & \\
\hline & & & & 57 & 48.1 & \multicolumn{2}{|c|}{$0.16[0.06,0.40]$} & \multirow{2}{*}{-} & \multirow{2}{*}{ 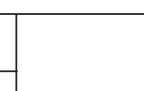 } & \\
\hline & 12 & 50 & 21 & 50 & 51.9 & $0.44[0.18,1.03]$ & & & & \\
\hline Total (95\% CI) & & 107 & & 107 & 100.0 & $0.27[0.10,0.73]$ & & & & \\
\hline Total events & 19 & & 48 & & & & & & & \\
\hline \multirow{2}{*}{\multicolumn{6}{|c|}{$\begin{array}{l}\text { Heterogeneity: } \operatorname{tau}^{2}=0.32 ; \mathrm{chi}^{2}=2.50, \mathrm{df}=1(P=0.11) ; I^{2}=60 \% \\
\text { Test for overall effect: } Z=2.57(P=0.01)\end{array}$}} & & 0.005 & 0.1 & 10 & 200 \\
\hline & & & & & & & Favour & erimental) & Favours ( & \\
\hline
\end{tabular}

Figure 7: Forest plot of endometrial type $B+C$.

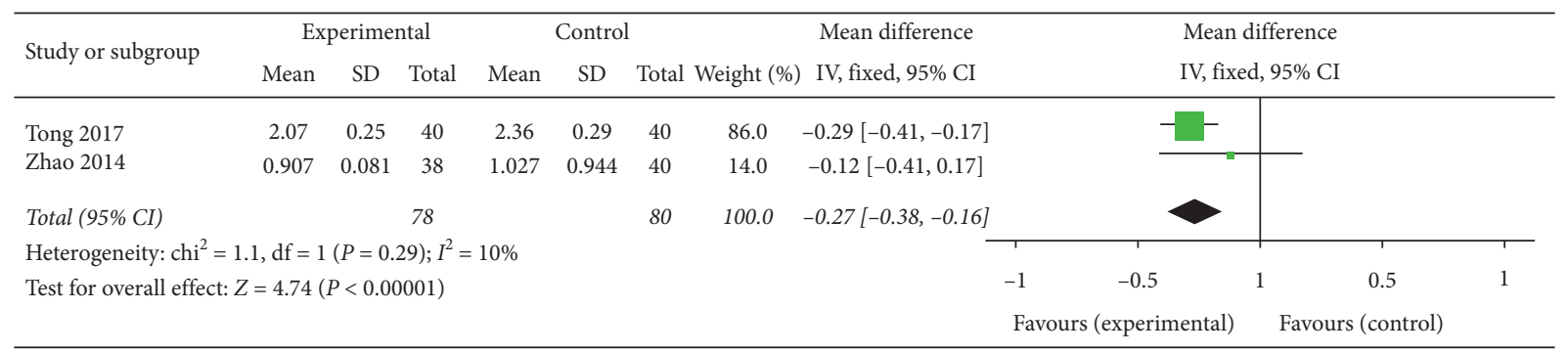




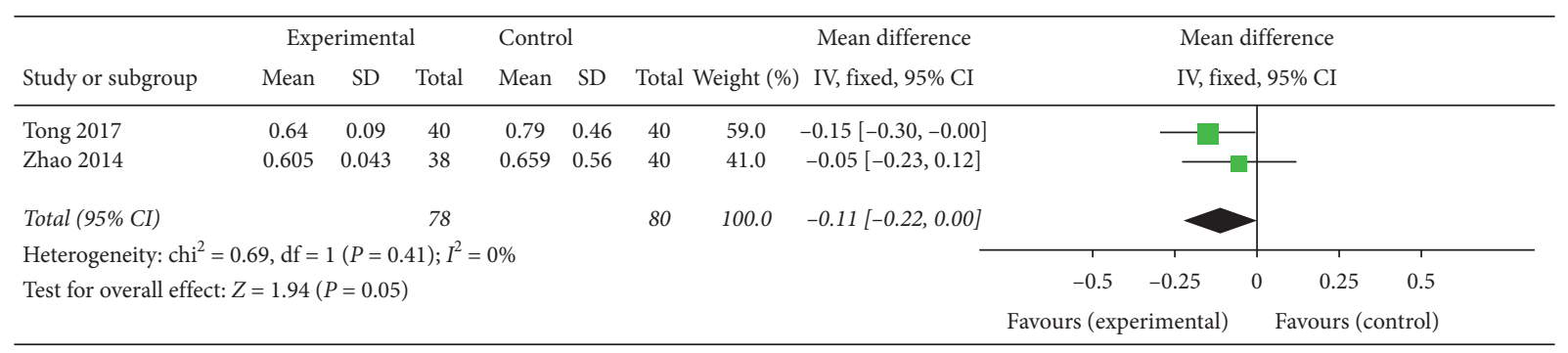

FIGURE 9: Forest plot of RI.

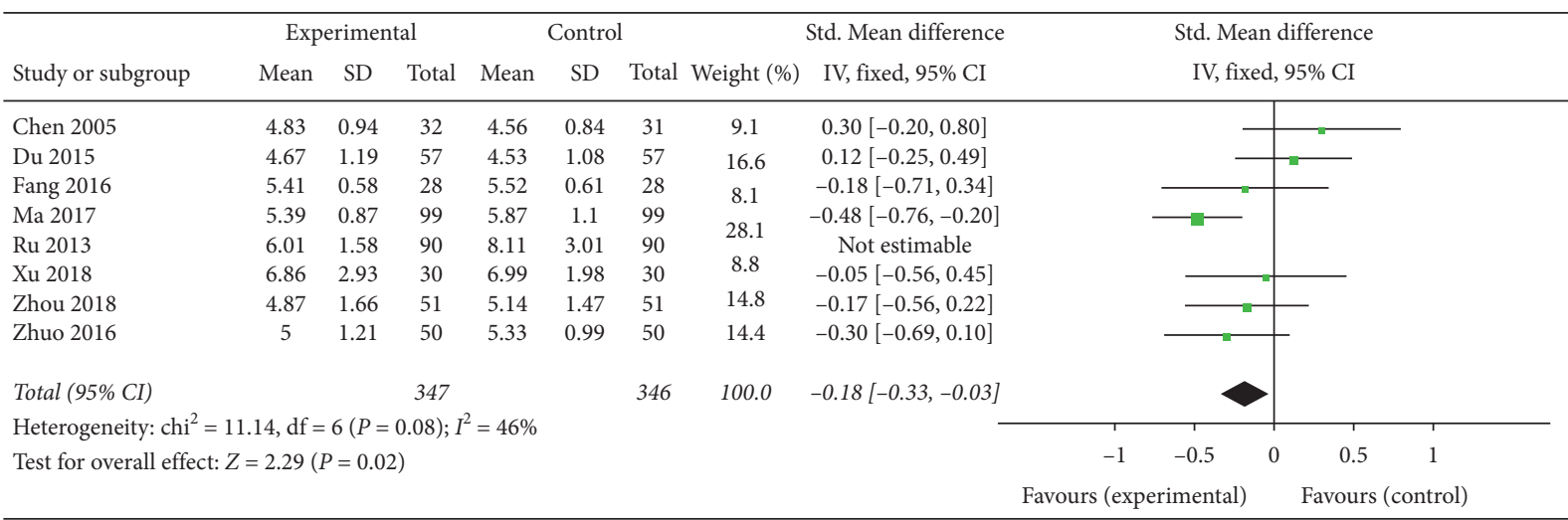

Figure 10: Forest plot of FSH levels.

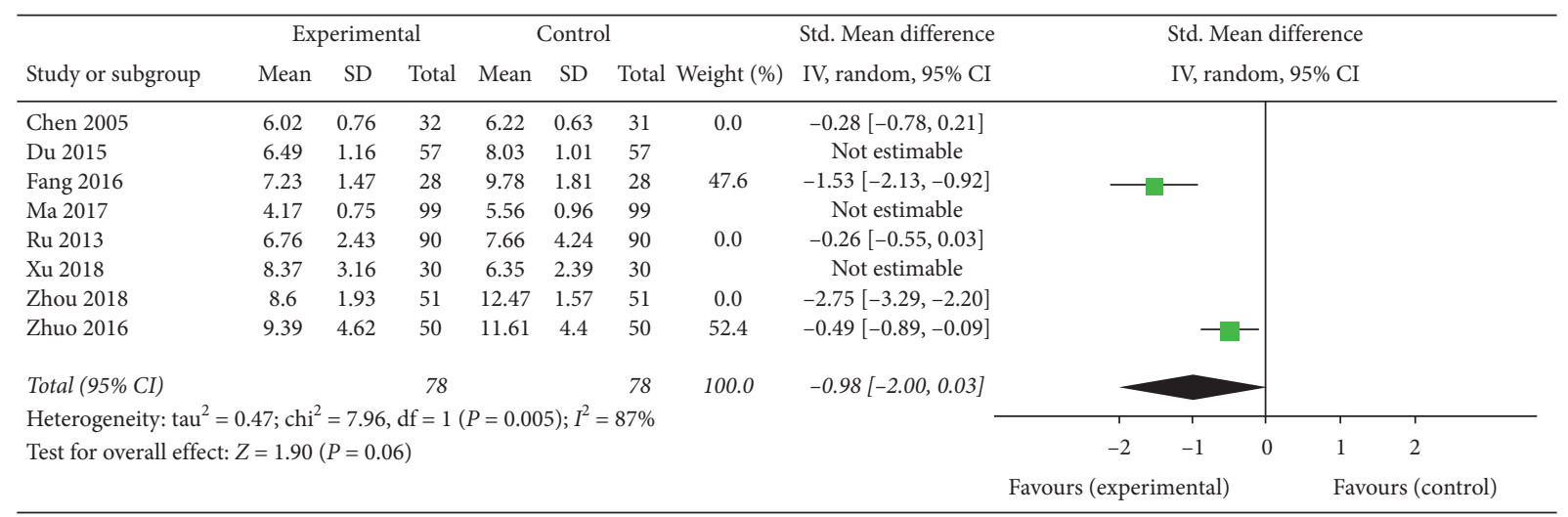

FIGURE 11: Forest plot of LH levels: TCM or acupuncture + WM vs. WM.

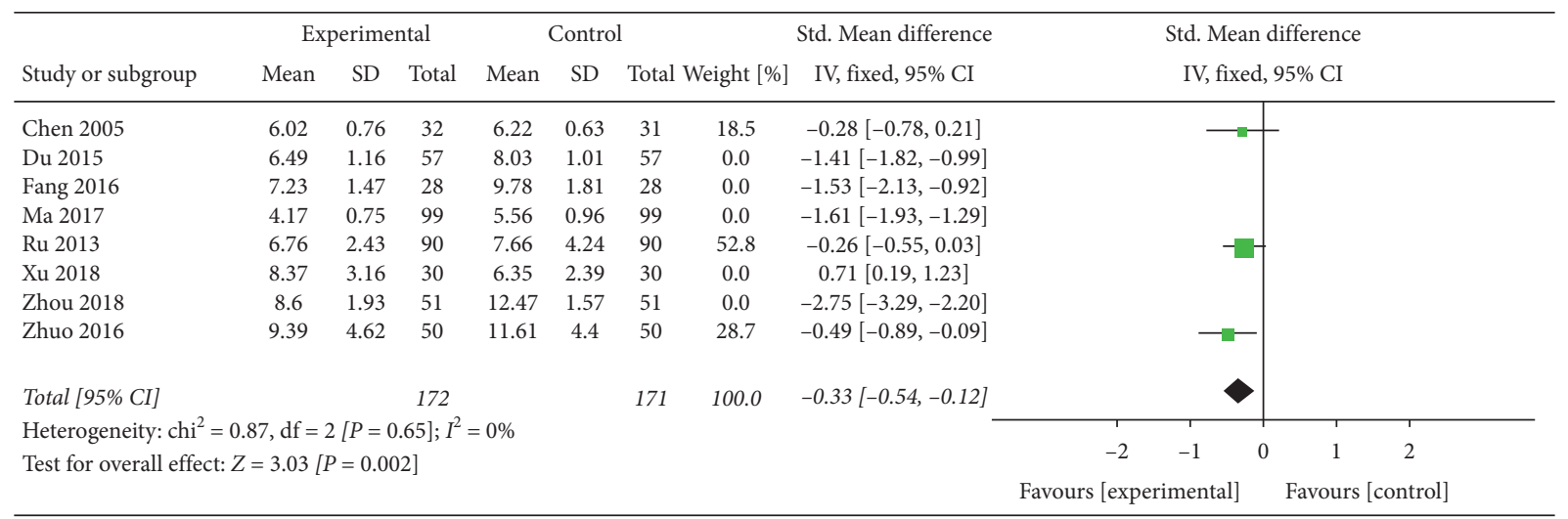

FIgURE 12: Forest plot of LH levels: acupuncture or TCM + WM vs. WM. 


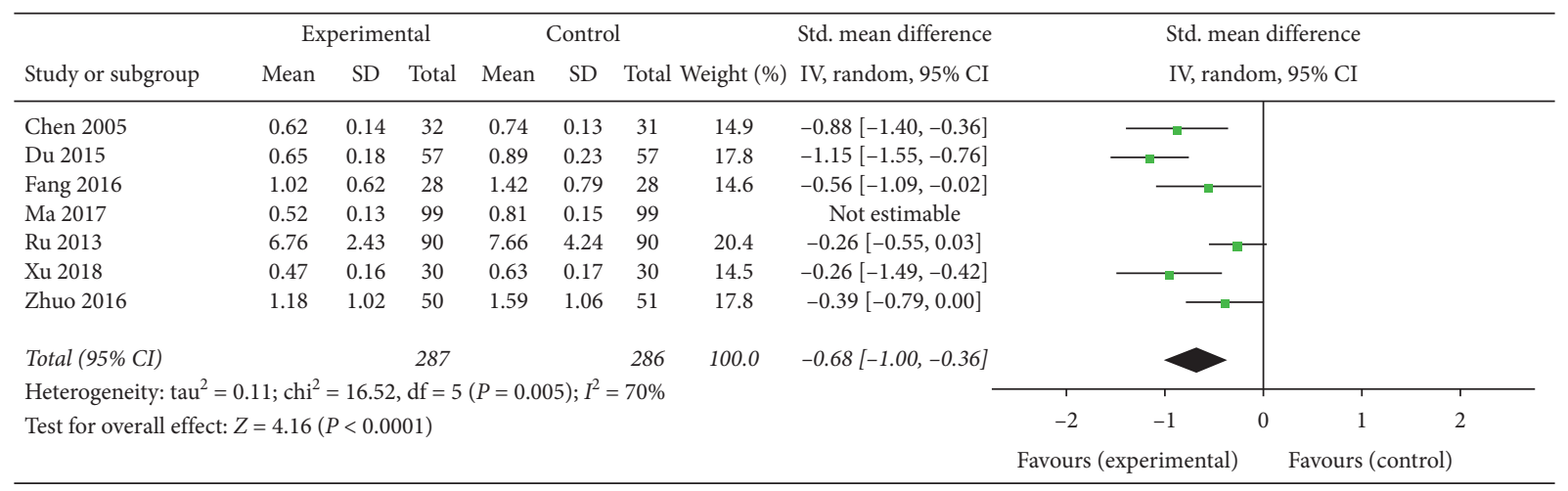

Figure 13: Forest plot of testosterone levels.

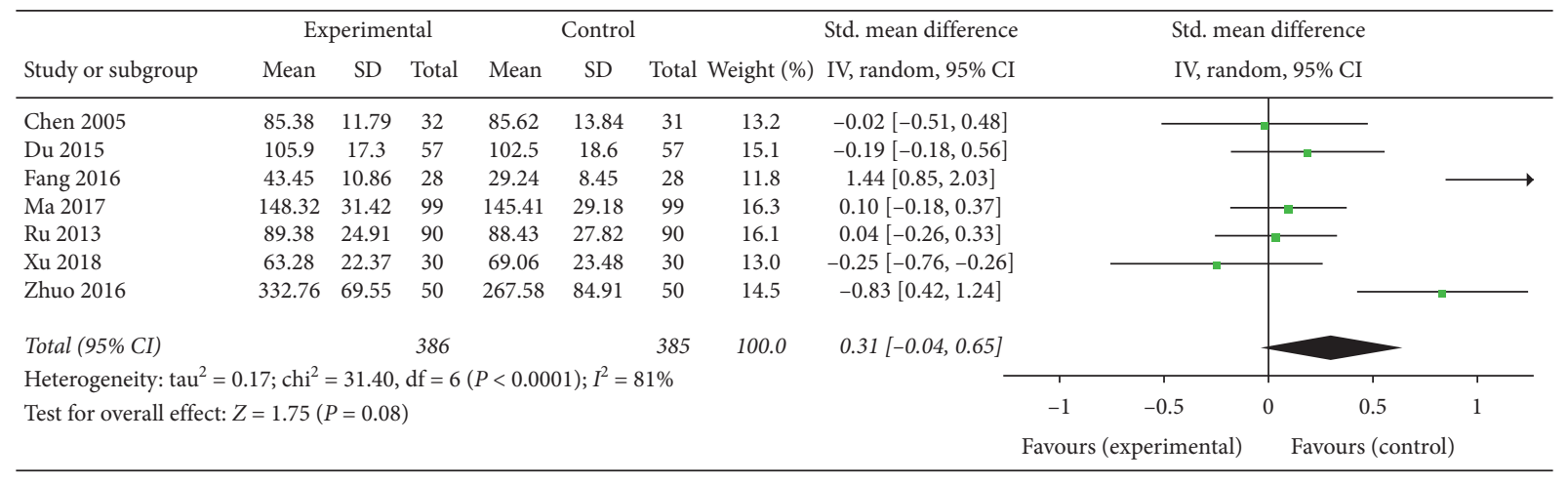

FIgURE 14: Forest plot of $E_{2}$ levels.

number of dominant follicles in PCOS patients after ovulation stimulation treatment (MD $-0.12,95 \%$ CI $[-0.22$, -0.03 ]; $I^{2}=0 \%, P=0.008$ ) [26, 30] (Figure 15).

3.1.6. Number of Ovulation Cases (Ovulation Rate). Nine trials involving 847 patients [21-25, 28, 30, 32, 33] showed that the number of ovulation cases (as indicated by signs of ovulation monitored by transvaginal ultrasound over a period of at least 2 months) was significantly increased in those treated with CAM (acupuncture or oral TCM) alone or in combination with western medicine compared to controls (clomiphene or Diane-35) (RR 1.34, 95\% CI [1.23, 1.46]; $I^{2}=31 \%, P<0.00001$ ) (Figure 16).

3.1.7. Pregnancy Rate. Nine articles involving 923 patients $[21,23,25,28-33]$ showed that acupuncture treatment alone or in combination with western medicine effectively improved the pregnancy rate of PCOS patients (as determined by urine HCG or blood $\beta$-HCG positivity along with simultaneous ultrasound showing the gestational sac and fetal heart beat) and that oral TCM in combination with western medicine also showed significant improvements in the pregnancy rate of PCOS patients (RR 1.59, 95\% CI $[1.30,1.93] ; I^{2}=51 \%, P<0.00001$ ) (Figure 17).
3.1.8. Abortion Rate. Three articles involving 130 patients $[29,30,32]$ found that CAM (oral TCM or acupuncture) in combination with western medicine for ovulation simulation was more effective in inhibiting the occurrence of abortion compared with western medicine treatment alone (RR 0.30, 95\% CI [0.09, 0.93]; $I^{2}=0 \%, P=0.04$ ) (Figure 18).

3.1.9. Ovarian Volume. As indicated by two articles involving 261 patients [21, 27], the PCOS patients administered oral TCM in combination with western medicine had greater reductions in ovarian volume compared to metformin or Diane-35 ( in MD -2.08, 95\% CI [-2.44, $-1.71] ; I^{2}=13 \%, \quad P<0.00001$ ) (Figure 19), which was considered a significant improvement in PCOS patients' condition.

3.1.10. Clinical Efficacy. In terms of clinical efficacy, the included trials fell into two groups, namely those that sought to improve the symptoms of PCOS and those that sought to improve the effective pregnancy rate of PCOS patients with infertility. Accordingly, the trials referring to clinical efficacy were integrated, and the clinical efficacy was set as the appearance of effective ovulation in the patients, i.e., the disappearance of mature follicles $\geq 15 \mathrm{~mm}$ or the collapse of the follicle wall as detected through vaginal ultrasound monitoring. Five trials involving 642 patients [22, 24, 26-28] 


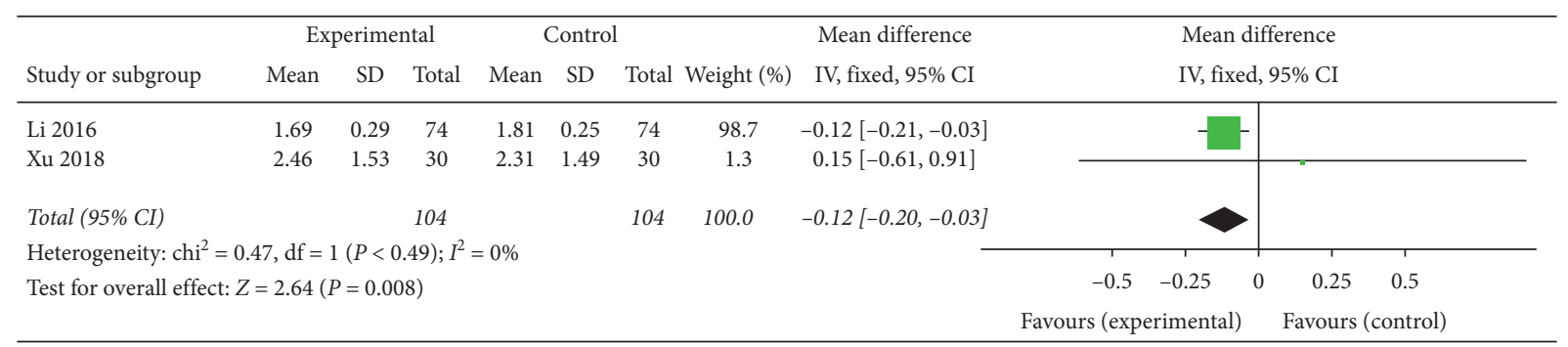

FIgURE 15: Forest plot of dominant follicle count.

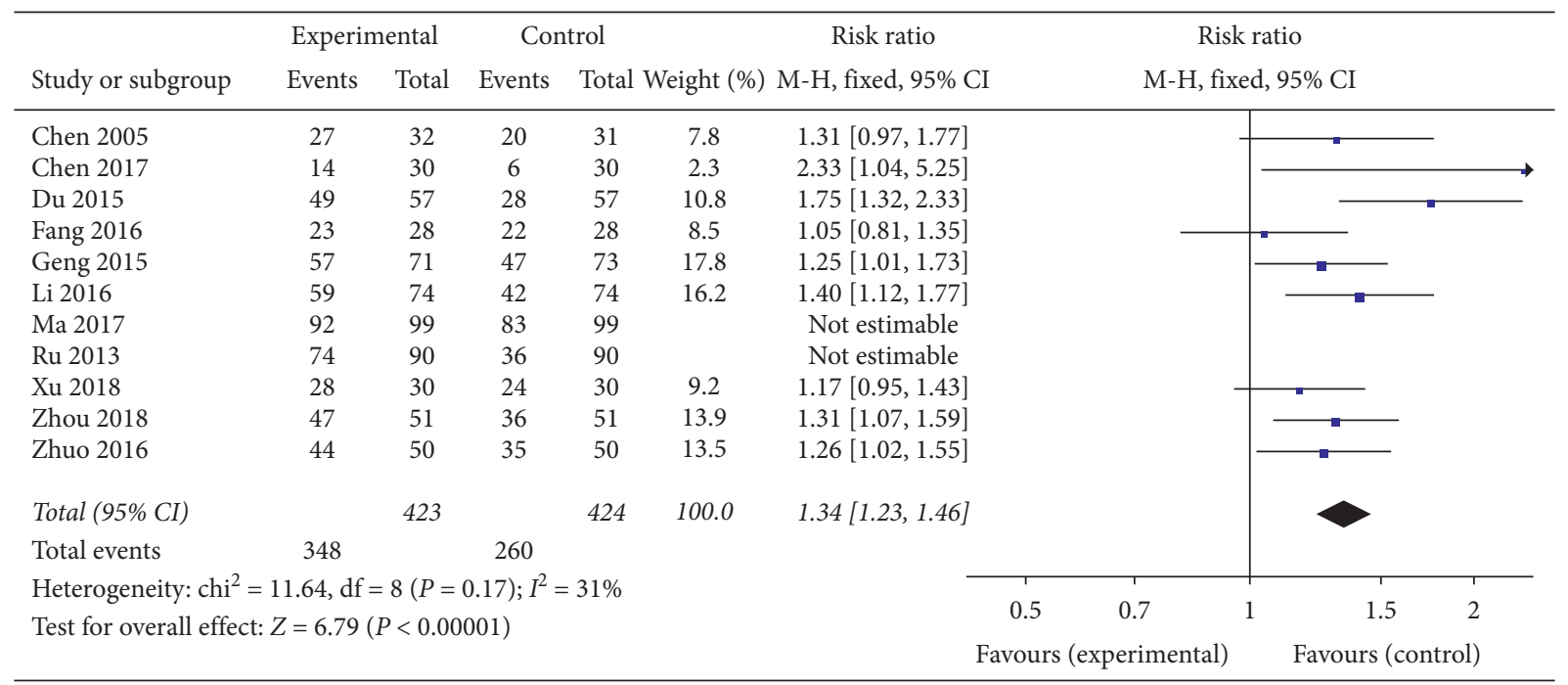

FIGURE 16: Forest plot of the ovulation rate.

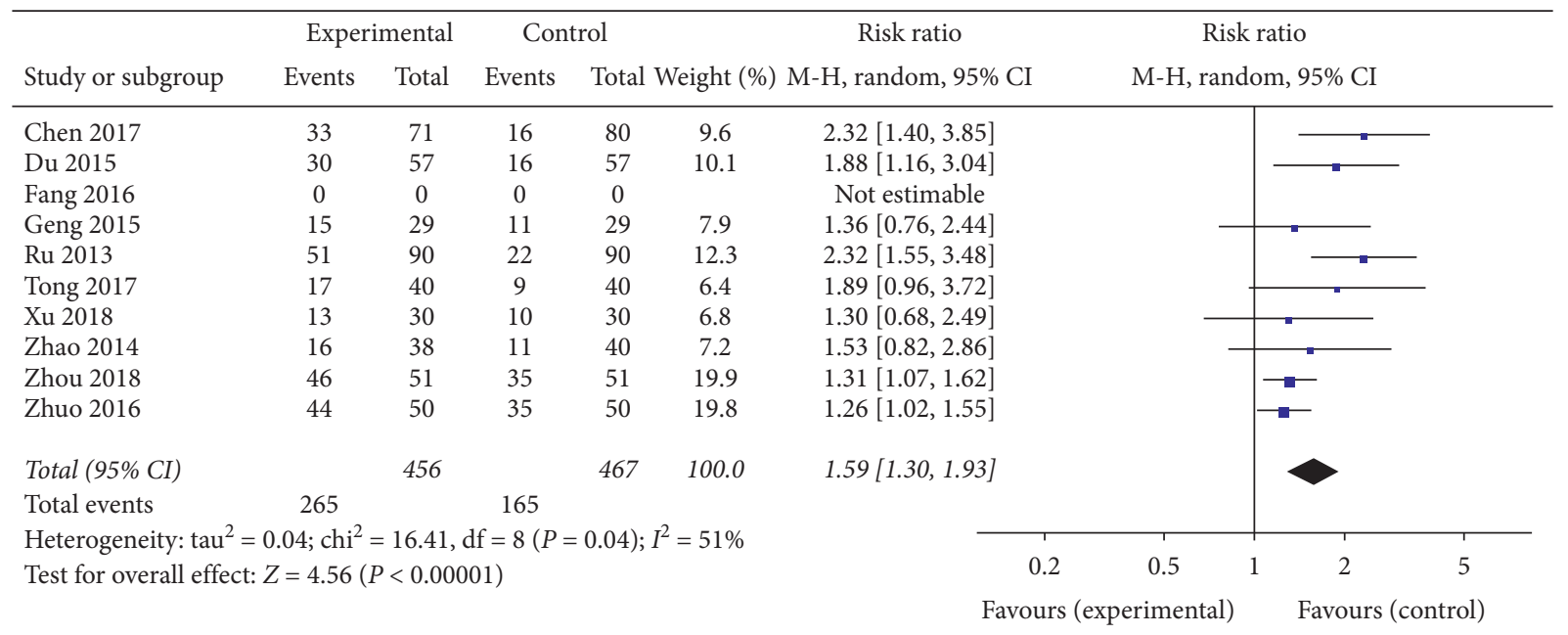

FIGURE 17: Forest plot of level of the pregnancy rate.

showed that oral TCM alone or in combination with western medicine had an obvious clinical effect in PCOS patients (RR $1.18,95 \%$ CI $[1.10,1.27] ; I^{2}=14 \%, P<0.00001$ ) (Figure 20). Specifically, oral TCM alone [24, 26] was more effective for ovulation simulation compared with western medicine alone (HMG + HCG).
3.1.11. TCM Syndrome Score. Two articles involving 346 patients mentioned the effects of treatments on TCM syndrome differentiation $[26,27]$, and the TCM syndrome score was determined by a score table as a final indicator of the treatment's effectiveness. However, the results of the two articles for the TCM syndrome score after CAM treatment 


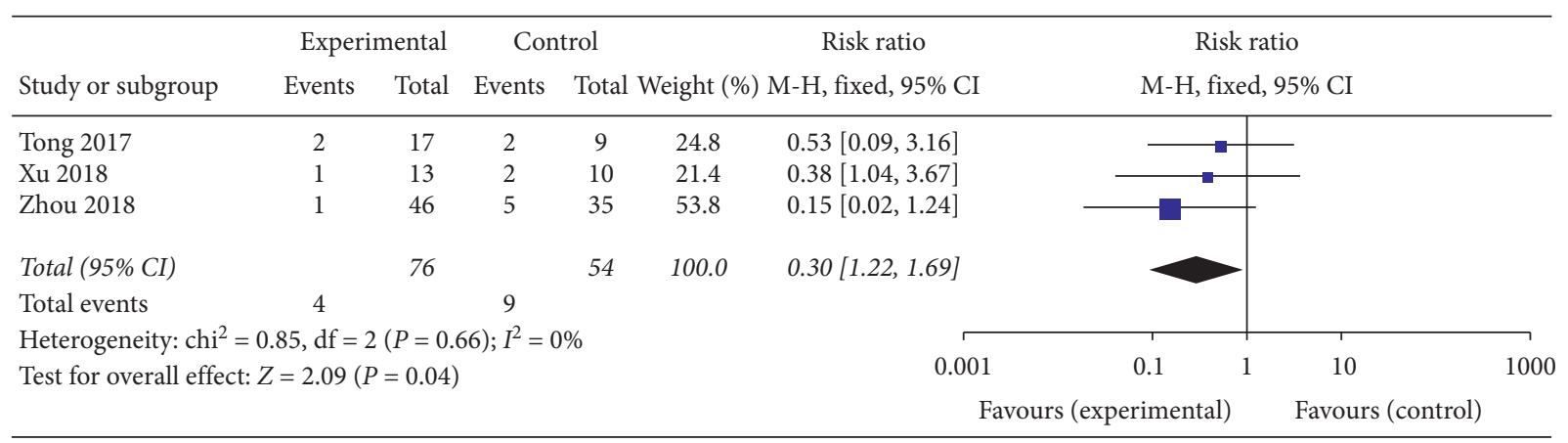

FIGURE 18: Forest plot of the abortion rate.

\begin{tabular}{|c|c|c|c|c|c|c|c|c|c|c|c|c|}
\hline \multirow{3}{*}{$\begin{array}{l}\text { Study or subgroup } \\
\text { Chen } 2005\end{array}$} & \multicolumn{3}{|c|}{ Experimental } & \multicolumn{3}{|c|}{ Control } & \multirow[b]{2}{*}{ Weight (\%) } & \multirow{2}{*}{$\begin{array}{l}\text { Mean difference } \\
\text { IV, fixed, 95\% CI }\end{array}$} & \multirow{2}{*}{\multicolumn{4}{|c|}{$\begin{array}{l}\text { Mean difference } \\
\text { IV, fixed, } 95 \% \mathrm{CI}\end{array}$}} \\
\hline & Mean & SD & Total & Mean & SD & Total & & & & & & \\
\hline & 8 & 5 & 32 & 11.5 & 5.6 & 31 & 1.9 & $-3.50[-6.12,-0.88]$ & & - & & \\
\hline Ma 2017 & 7.07 & 1.03 & 99 & 9.12 & 1.57 & 99 & 98.1 & $-2.05[-2.42,-1.68]$ & & & & \\
\hline Total (95\% CI) & & & 131 & & & 130 & 100.0 & $-2.08[-2.44,-1.71]$ & & 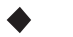 & & \\
\hline \multicolumn{9}{|c|}{ Heterogeneity: $\mathrm{chi}^{2}=1.15, \mathrm{df}=1(P=0.28) ; I^{2}=13 \%$} & -4 & -2 & 2 & 4 \\
\hline \multicolumn{9}{|c|}{ Test for overall effect: $Z=11.12(P<0.00001)$} & Favours (exp & mental) & \multicolumn{2}{|c|}{ Favours (control) } \\
\hline
\end{tabular}

FigURE 19: Forest plot of ovarian volume.

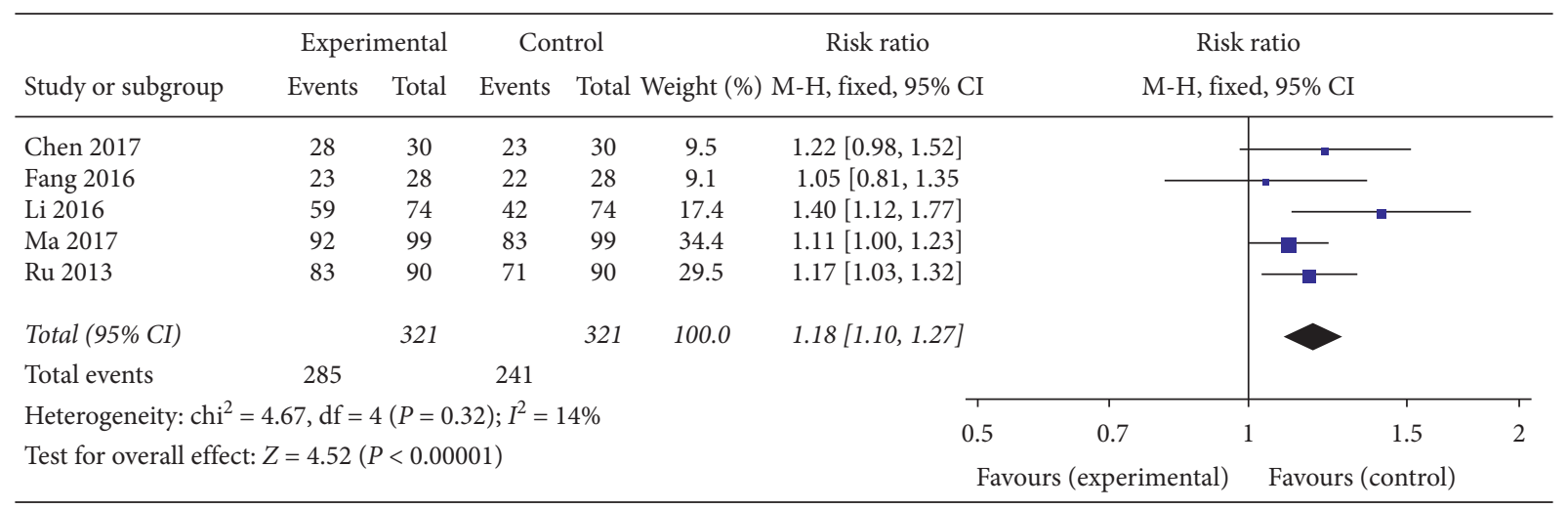

Figure 20: Forest plot of clinical efficacy.

were not significantly different (SMD $-4.33,95 \%$ CI $[-7.51$, $-1.16] ; \mathrm{I}^{2}=98 \%, P=0.007$ ) (Figure 21).

3.1.12. Cervical Mucus Score. As suggested by two articles involving 214 patients, $[23,33]$ CAM (acupuncture) or CAM (oral TCM) combined with clomiphene treatment significantly elevated cervical mucus score compared with clomiphene alone (MD 1.73, 95\% CI [1.37, 2.09]; $I^{2}=0 \%$, $P<0.00001$ ) (Figure 22).

3.1.13. Adverse Reactions. Three articles [25, 30, 32] mentioned adverse reactions (e.g., luteinized unruptured follicle syndrome and ovarian hyperstimulation syndrome) during ovulation simulation treatment. Compared with the patients treated with Diane-35 or clomiphene alone, the proportion of adverse reactions in patients administrated with CAM (oral TCM or acupuncture) in combination with western medicine was significantly reduced (RR 0.48, 95\% CI [0.31, $0.74] ; I^{2}=50 \%, P=0.001$ ) (Figure 23).

One article [21] reported that TCM in combination with Diane-35 and Diane-35 alone effectively reduced the endometrial thickness and ovarian volume and significantly improved the number of dominant follicles. However, after six cycles after discontinuation of treatment, the endometrial thickness and ovarian volume of the western medicine control group were close to the pretreatment status, while the CAM intervention group effectively maintained the normal levels.

In one article, due to the additional intervention of aspirin in both groups, we could not absolutely attribute the effectiveness to CAM in determining the outcome indicators 


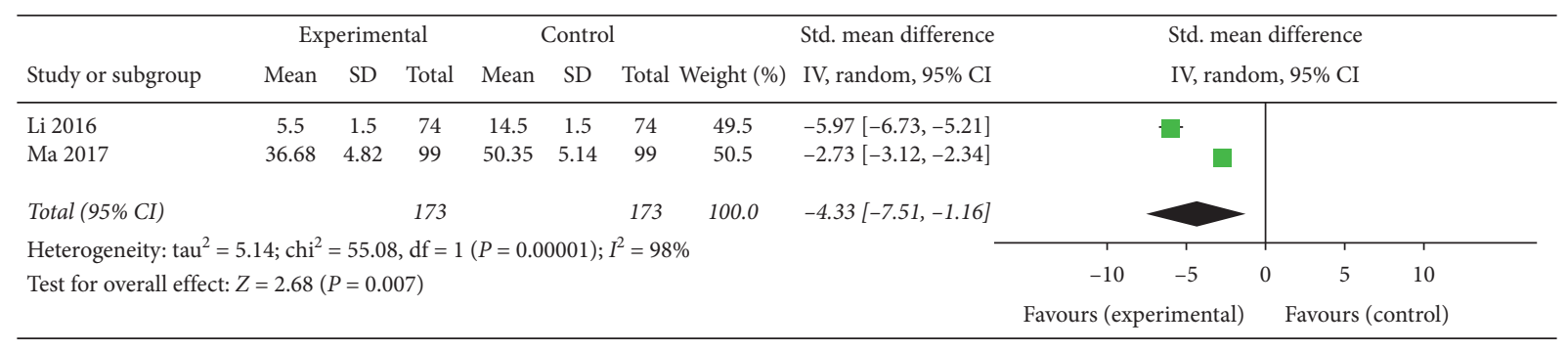

Figure 21: Forest plot of the TCM syndrome score.

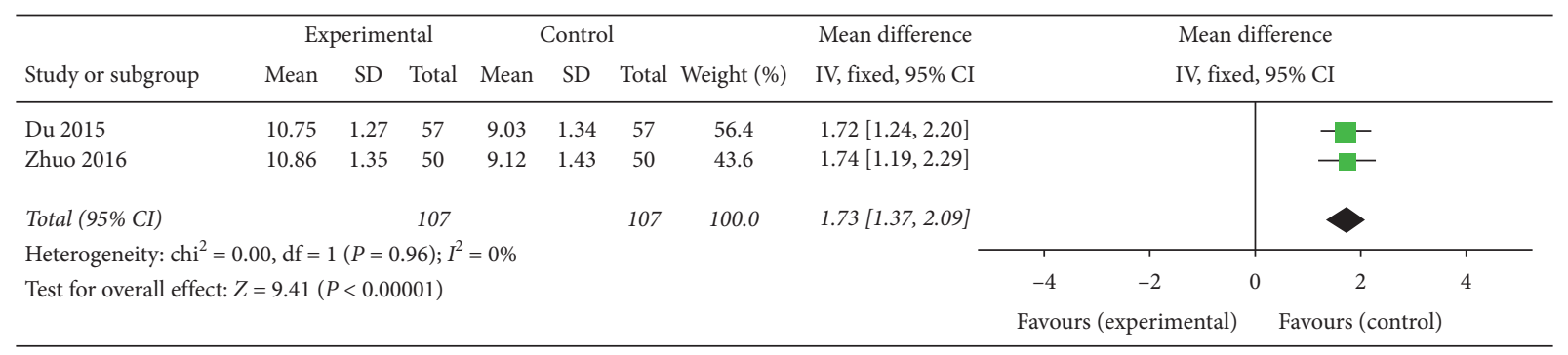

FIGURE 22: Forest plot of the cervical mucus score.

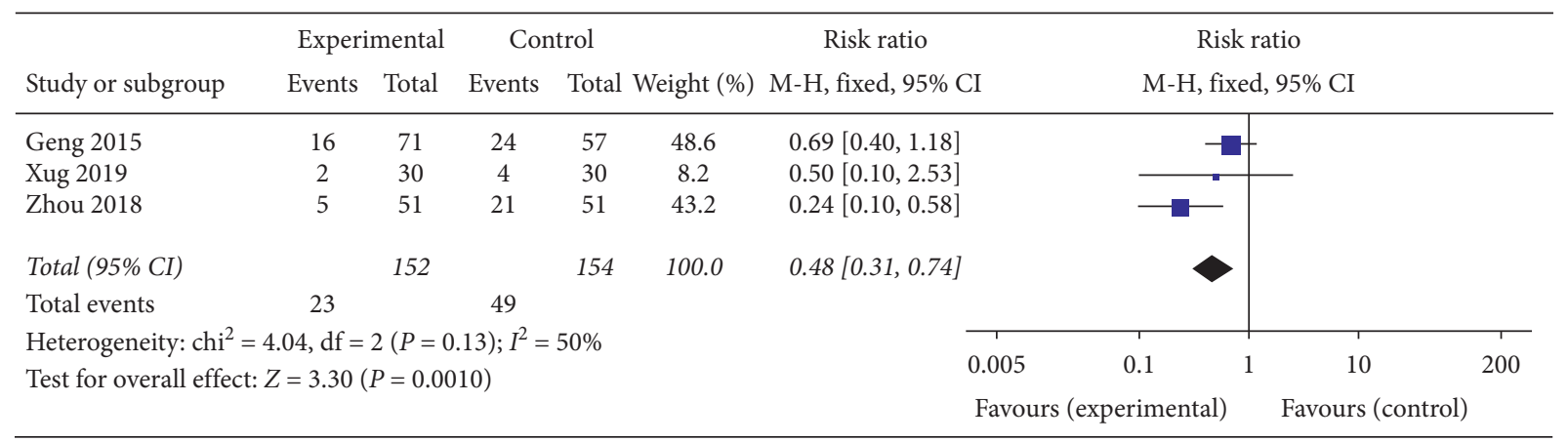

Figure 23: Forest plot of the number of adverse reactions.

when compared with the western medicine control group [31].

3.1.14. Additional Analysis. Because fewer than 10 trials were contained in each comparison, this study could not conduct meaningful funnel chart analysis to determine publication bias. In addition, the heterogeneity of the endometrial thickness and the LH level reached over 70\% $\left(I^{2} \geq 70 \%\right)$, so a subgroup meta-analysis was conducted. Different types of CAM were used in the included RCTs, and this resulted in a certain level of clinical heterogeneity in the results of this study.

\section{Discussion}

This review identified 13 RCTs involving 1,297 PCOS patients with abnormal endometrial status. The normal endometrial stages include proliferation, secretion, and menstrual periods, and thus the thickness of the endometrium changes over the course of the menstrual cycle. Most researchers consider that if the endometrium is extremely thin $(<8 \mathrm{~mm})$, this might cause unfavorable condition for embryo implantation and thus result in a low clinical pregnancy rate, and extreme thickness $(>16 \mathrm{~mm})$ might also reduce the clinical pregnancy rate [34]. Accordingly, as indicated from the results presented here, CAM therapy (including CAM therapies used alone as well as CAM therapies used in combination with traditional western medicine) is capable of effectively reducing the thickness of the endometrium in pathological hyperplasia, while in PCOS patients with infertility it can increase the thickness of the endometrium during ovulation thereby improving the status of the endometrium, increasing the pregnancy rate, and decreasing the abortion rate. Thus, depending on the patient's condition, CAM can reduce or increase the thickness of the endometrium as needed to promote pregnancy more effectively than traditional western medicine and can help to 
avoid long-term complications such as endometrial cancer. Compared with western medicine (e.g., clomiphene, Diane35 , and other ovulation simulation treatments), CAM is capable of significantly reducing the adverse reactions associated with ovulation simulation, improving cervical mucus score, increasing ovulation rate, increasing the number of dominant follicles, and increasing the pregnancy rate, thus showing an overall clinical effect of CAM treatments.

Furthermore, this review also focused on the impact of CAM treatment on the hormone levels in PCOS patients. Although $E_{2}$ is directly involved in hyperplasia of the endometrium, CAM does not noticeably affect the $E_{2}$ level of PCOS patients. This may be related to the small number of articles included. FSH and $\mathrm{LH}$, as gonadotropins, are not directly involved in the cyclic changes of endometrial hyperplasia and secretion, but regulation of their receptors can affect the intracellular function of the glandular epithelium of the endometrium where the receptors are expressed [35]. Gonadotropin receptor levels are positively correlated with the development of endometrial cancer [36], and it is known that exposure to high-level FSH conditions can increase the proliferation, invasion, and metastasis of endometrial cancer cells [37]. The results of the present analysis strongly suggest that CAM is capable of effectively reducing the serum FSH level in PCOS patients and thus reducing the risk of endometrial cancer. Moreover, this study found that CAM can reduce the serum testosterone level in PCOS patients with endometrial abnormalities. The elevation of testosterone is considered one of the common symptoms in PCOS patients, and testosterone, as a type of androgen, suppresses the autoimmune system [38] and can lead to cancer. Patients with endometrial cancer and endometrial adenoma often show elevated levels of testosterone $[39,40]$, and thus by reducing the level of testosterone CAM might prevent long-term complications such as endometrial cancer in PCOS patients.

The normalization of the endometrium, which is a necessary condition for successful pregnancy, is a critical outcome indicator for PCOS patients. Type A endometrium is more conducive to pregnancy due to its richer blood supply and higher receptivity than types B and C [41], and this review found that CAM significantly increases the occurrence of type A endometrium thus suggesting that CAM can improve the pregnancy rate in PCOS patients. By ameliorating abnormalities of the endometrium, CAM positively affected the pregnancy rate and live birth rate in PCOS patients, thus further proving that PCOS patients with complications (e.g., infertility) can be effectively treated with CAM.

According to the existing literature, the abnormal proliferation of the endometrium in PCOS patients shows a close positive correlation with the expression of prolactin and its receptors [42]. One of the included RCTs involved 80 PCOS patients and 80 matching controls and showed that the visfatin protein in the endometrial tissue of PCOS patients was highly upregulated and that the phosphorylation of AKT and ERK1/2 was also significantly increased, thus indicating that the malignant transformation of the endometrium in PCOS patients might be associated with the visfatin protein and the activation of the AKT and ERK1/2 signaling pathways [43]. Moreover, the abnormal state of the endometrium in PCOS patients can be manifested as insulin resistance contributing to abnormal glucose metabolism [44]. It has been reported that the endometrium of PCOS patients might suffer from abnormal amino acid metabolism in the tryptophan, tyrosine, and phenylalanine pathways, thereby causing abnormal cell proliferation and decreasing endometrial receptivity [45]. In the trials included here, however, none studied the effects of CAM on the factors that have been reported to cause endometrial abnormalities, and thus it remains unclear if CAM can effectively ameliorate the abnormalities of the endometrium after the related pathogenic factors mentioned above have been appropriately regulated.

While the endometrial problems in PCOS patients have aroused huge attention [46-49], CAM has not been valued as a primary method to improve the endometrial status in these patients. However, CAM has been found to be increasingly employed in controlling body weight and improving hormone levels and ovulation rates in PCOS patients $[10,50,51]$. Most of the studies included here have bias risk in numerous areas (e.g., distribution concealment, blindness, data loss, and sample size calculation), and thus the effectiveness of CAM remains unclear.

4.1. Strengths and Limitations. The present meta-analysis systematically evaluated the efficacy and safety of CAM in treating endometrial lesions in patients with PCOS. Although this study searched as many trials as possible, we still cannot be sure that we have covered all the evidence, and there might still be unanalyzed or unpublished data that might influence our conclusions. Additionally, in the retrieval process factors such as exercise, diet intervention, and psychological influences were not considered, so omissions and deficiencies might have occurred in the retrieval of RCTs studying CAM therapy. The final 13 RCTs included here focused on TCM treatment, and the research subjects and researchers almost exclusively originated from mainland China, and thus there was a lack of research information about other regions, which may have caused other bias. Moreover, most of the included RCTs lacked clear double-blind design methods, resulting in the low quality of the included RCTs. Furthermore, due to the statistical heterogeneity and variability of the CAM methods, subgroup meta-analysis, meaningful sensitivity analysis, and funnel chart analysis could not be conducted. Thus the present systematic review is limited in terms of the validity and universality of its conclusions, and this suggests that future RCTs should be designed as multicenter, double-blind placebo-controlled trials with more indicators of effectiveness, and they should be reported in accordance with the CONSORT (Consolidated Standards for Reporting Trials) criteria [52]. 


\section{Conclusion}

This systematic review suggests that CAM has potential for improving endometrial thickness, endometrial type, serum hormone level, and pregnancy rate in PCOS patients. However, due to the limited quantity and the general low quality of the methodology of the included trials, more indepth research is required before CAM can be applied more widely in clinical practice. Thus more rigorous double-blind, placebo-controlled trials should be conducted to confirm the efficacy of CAM in improving endometrial condition in PCOS patients.

\section{Data Availability}

The data for this study are available from the corresponding author upon request.

\section{Conflicts of Interest}

The authors declare that they have no relevant conflicts of interest.

\section{Authors' Contributions}

Jiayu $\mathrm{Hu}$ designed the study, analyzed the data, and drafted the manuscript. Wenhua Shi assisted in writing the manuscript and corrected the grammar and writing. Jiayue Xu and Shaoxuan Liu collected the data. Siya $\mathrm{Hu}$ and Wenjing $\mathrm{Fu}$ collected the data and assessed the methodological quality of the included trials. Jing Wang and Fengjuan Han conceptualized the study and reviewed the protocol for important intellectual content. Jiayu $\mathrm{Hu}$ and Wenhua Shi contributed equally to this work.

\section{Acknowledgments}

This study was financed by the National Natural Science Foundation of China (no. 82074484) and the National Administration of Traditional Chinese Medicine (no. JDZX2012038).

\section{References}

[1] E. Diamanti-Kandarakis, C. R. Kouli, A. T. Bergiele et al., "A survey of the polycystic ovary syndrome in the Greek island of lesbos: hormonal and metabolic profile," The Journal of Clinical Endocrinology \& Metabolism, vol. 84, no. 11, pp. 4006-4011, 1999.

[2] G. Bozdag, S. Mumusoglu, D. Zengin, E. Karabulut, and B. O. Yildiz, "The prevalence and phenotypic features of polycystic ovary syndrome: a systematic review and metaanalysis," Human Reproduction, vol. 31, no. 12, pp. 2841-2855, 2016.

[3] R. Azziz, K. S. Woods, R. Reyna, T. J. Key, E. S. Knochenhauer, and B. O. Yildiz, "The prevalence and features of the polycystic ovary syndrome in an unselected population," The Journal of Clinical Endocrinology \& Metabolism, vol. 89, no. 6, pp. 2745-2749, 2004.

[4] R. Li, Q. Zhang, D. Yang et al., "Prevalence of polycystic ovary syndrome in women in China: a large community-based study," Human Reproduction, vol. 28, no. 9, pp. 2562-2569, 2013.

[5] V. Chandra, J. J. Kim, D. M. Benbrook et al., "Therapeutic options for management of endometrial hyperplasia," Journal of Gynecologic Oncology, vol. 27, no. 1, 2016.

[6] J. A. Barry, M. M. Azizia, and P. J. Hardiman, "Risk of endometrial, ovarian and breast cancer in women with polycystic ovary syndrome: a systematic review and metaanalysis," Human Reproduction Update, vol. 20, no. 5, pp. 748-758, 2014.

[7] B. A. Lessey and S. L. Young, "What exactly is endometrial receptivity?" Fertility and Sterility, vol. 111, no. 4, pp. 611-617, 2019.

[8] K. Kato, K. Ezoe, A. Yabuuchi et al., "Comparison of pregnancy outcomes following fresh and electively frozen single blastocyst transfer in natural cycle and clomiphene-stimulated IVF cycles," Human Reproduction Open, vol. 2018, no. 3, 2018.

[9] R. Nidhi, V. Padmalatha, R. Nagarathna, and R. Amritanshu, "Effects of a holistic yoga program on endocrine parameters in adolescents with polycystic ovarian syndrome: a randomized controlled trial," The Journal of Alternative and Complementary Medicine, vol. 19, no. 2, pp. 153-160, 2013.

[10] L. H. Sordia-Hernández, P. Ancer Rodríguez, D. S. Rodriguez et al., "Effect of a low glycemic diet in patients with polycystic ovary syndrome and anovulation -A randomized controlled trial," Clinical and Experimental Obstetrics \& Gynecology, vol. 43, no. 4, pp. 555-559, 2016.

[11] J. B. Correa, S. L. Sperry, and J. Darkes, "A case report demonstrating the efficacy of a comprehensive cognitivebehavioral therapy approach for treating anxiety, depression, and problematic eating in polycystic ovarian syndrome," Archives of Women's Mental Health, vol. 18, no. 4, pp. 649-654, 2015.

[12] K. Hoeger, "Exercise therapy in polycystic ovary syndrome," Seminars in Reproductive Medicine, vol. 26, no. 1, pp. 093-100, 2008.

[13] The Rotterdam ESHRE/ASRM-Sponsored PCOS Consensus Workshop Group, "Revised 2003 consensus of diagnostic criteria and long-term health risks related to polycystic ovary syndrome (PCOS)," Human Reproduction, vol. 19, pp. 41-47, 2004.

[14] Z. J. Chen, Y. W. Zhang, J. Y. Liu et al., "Health Industry standards for the Diagnosis of polycystic ovary syndrome in the People'sRepublic of China," Chinese Journal of Obstetrics and Gynecology, vol. 47, no. 1, pp. 74-75, 2012.

[15] S. Arentz, C. A. Smith, J. Abbott et al., "Nutritional supplements and herbal medicines for women with polycystic ovary syndrome; a systematic review and meta-analysis," BMC Complementary and Alternative Medicine, vol. 17, no. 1, p. 500, 2017.

[16] S. Victorin, "Acupuncture for infertility in women with polycystic ovary syndrome: what does it add?" Seminars in Reproductive Medicine, vol. 35, no. 4, pp. 353-358, 2017.

[17] M. Ratnakumari, N. Manavalan, D. Sathyanath, Y. Ayda, and K. Reka, "Study to evaluate the changes in polycystic ovarian morphology after naturopathic and yogic interventions," International Journal of Yoga, vol. 11, no. 2, pp. 139-147, 2018.

[18] D. Ujvari, M. Hulchiy, A. Calaby, A. Nybacka, B. Bystrom, and A. L. Hirschberg, "Lifestyle intervention up-regulates gene and protein levels of molecules involved in insulin signaling in the endometrium of overweight/obese women with polycystic ovary syndrome," Human Reproduction, vol. 29, no. 7, pp. 1526-1535, 2014. 
[19] W. Lin Annie, K. Maryam, Y. Jarrett Brittany et al., "Dietary and physical activity behaviors in women with polycystic ovary syndrome per the new international evidence-based guideline," Nutrients, vol. 11, no. 11, 2019.

[20] J. P. T. Higgins and S. Green, Cochrane Handbook for Systematic Reviews of Interventions Version 5.1.0, https://training. cochrane.org/handbook, 2011.

[21] C. L. Sheng, "Clinical research on combined therapy of diane-35 with modified yougui pill on polycystic ovarian syndrome," Chinese Journal of Integrated Traditional \& Western Medicine, vol. 25, no. 9, pp. 794-796, 2005.

[22] L. Chen, Y. Tan, and S. P. Chen, "Effect of clomiphene citrate and Dingkun Dan on ovulation induction and clinical pregnancy of polycystic ovary syndrome," China Journal of Chinese Materia Medica, vol. 42, no. 20, p. 4035, 2017.

[23] J. Du, "Effect of bushen tiaojing decoction in promoting ovulation among polycystic ovarian syndrome barrenness patients," Chinese Journal of Experimental Traditional Medical Formulae, vol. 21, no. 16, pp. 171-174, 2015.

[24] F. Qingxia, Z. Ping, and L. I. Shenyin, "Clinical study on bushen cupai decoction treating 56 cases of polycystic ovarian syndrome ovulation dysfunction infertility," Journal of Traditional Chinese Medicine, vol. 57, no. 11, pp. 942-945, 2016.

[25] G. Hongling and X. Limian, "Clinical observation on treatment of polycystic ovarian syndrome caused sterility by using TCM periodic therapy during ovulation induction," Chinese Journal of Experimental Traditional Medical Formulae, vol. 21, no. 10, pp. 178-181, 2015.

[26] X. Y. Li, "Clinical research of culuanpao decoction in the treatment of ovulation failure in polycystic ovarian syndrome grace," Acta Chinese Medicine, vol. 31, no. 6, pp. 861-864, 2016.

[27] M. Jing, W. Xuewei, and P. Zhouli, "Combined Chinese and western medicine treatment influence on sex hormone levels of polycystic ovary syndrome," Liaoning Journal of Traditional Chinese Medicine, vol. 44, no. 8, pp. 1692-1694, 2017.

[28] R. Xiuli, F. Liu, J. Liu et al., "Kidney-supplementing bloodquickening liver-clearing formula combined with clomiphene for 90 cases of polycystic ovary syndrome," Journal of Traditional Chinese Medicine, vol. 54, no. 14, pp. 1214-1216, 2013.

[29] T. Xingli, T. Yong, Y. Yanyun et al., "Sequential therapy combined with ovulation induction of PCOS in endometrium of infertile women," Chinese Traditional Patent Medicine, vol. 39, no. 12, pp. 2491-2496, 2017.

[30] J. Xu and Y. Zuo, "Efficacy of acupuncture as adjunctive treatment on infertility patients with polycystic ovary syndrome," Zhongguo Zhen Jiu, vol. 38, no. 4, pp. 358-361, 2018.

[31] Y. Zhao, B. Du, X. Jiang et al., "Effects of combining low-dose aspirin with a Chinese patent medicine on follicular blood flow and pregnancy outcome," Molecular Medicine Reports, vol. 10, no. 5, pp. 2372-2376, 2014.

[32] Z. Wenqin and F. Dianzhou, "Clinical observation of Tiaojing Cuyun Pills combined with Clomiphene in treatment of obesity polycystic ovarian syndrome infertility," Drugs \& Clinic, vol. 33, no. 4, pp. 926-929, 2018.

[33] Y. Zhuo, "The "regulating conception-governor vessel" acupuncture method for infertility of polycystic ovarian syndrome," Zhongguo Zhen Jiu, vol. 36, no. 12, pp. 1237-1241, 2016.

[34] Y. H. Jung, Y. Y. Kim, M. H. Kim, I. H. Park, Y. J. Yoo, and J. D. Jo, "Endometrial injury may promote implantation in patients with increased endometrial thickness on the day of hCG administration," Fertility and Sterility, vol. 100, no. 3, p. S388, 2013.
[35] S. Sandro, S. Paola, D. E. Chiara et al., "Evidence for expression and functionality of FSH and LH/hCG receptors in human endometrium," Journal of Assisted Reproduction \& Genetics, vol. 35, no. 9, pp. 1703-1712, 2018.

[36] S. Davies, C. M. R. Bax, E. Chatzaki et al., "Regulation of endometrial cancer cell growth by luteinizing hormone (LH) and follicle stimulating hormone (FSH)," British Journal of Cancer, vol. 83, no. 12, 2000.

[37] C. Yue-Qun, "Bu shen yang xue prescription has treating effect on endometrial cancer through FSH/PI3K/AKT/gankyrin/HIF- $\alpha$ /cyclinD 1 pathway in ishikawa cells," Evidence Based Complementary \& Alternative Medicine, vol. 2018, Article ID 8412984, 10 pages, 2018.

[38] A. Trigunaite, J Dimo, T. N. Rgensen, and T. N. Jørgensen, "Suppressive effects of androgens on the immune system," Cellular Immunology, vol. 294, no. 2, pp. 87-94, 2015.

[39] B. Pettersson, R. Bergström, and E. D. B. Johansson, "Serum estrogens and androgens in women with endometrial carcinoma," Gynecologic Oncology, vol. 25, no. 2, pp. 223-233, 1986.

[40] N. Vitoratos, O. Gregoriou, D. Hassiakos, and P. A. Zourlas, "The role of androgens in the late-premenopausal woman with adenomatous hyperplasia of the endometrium," International Journal of Gynecology \& Obstetrics, vol. 34, no. 2, pp. 157-161, 1991.

[41] I. Y. Järvelä, "Evaluation of endometrial receptivity during invitro fertilization using three-dimensional power Doppler ultrasound," Ultrasound in Obstetrics \& Gynecology, vol. 26, no. 7, pp. 765-769, 2005.

[42] P. Mariana, N. Gunnar, S. Lena et al., "Association between prolactin receptor expression and proliferation in the endometrium of obese women with polycystic ovary syndrome," Gynecological Endocrinology: The Official Journal of the International Society of Gynecological Endocrinology, vol. 36, no. 3, 2020.

[43] W. Tian, H. Zhang, Y. Zhang et al., "High level of visfatin and the activation of Akt and ERK1/2 signaling pathways are associated with endometrium malignant transformation in polycystic ovary syndrome," Gynecological Endocrinology, vol. 36, no. 2, pp. 1-6, 2019.

[44] H. Cabrera-Cruz, O. Lorena, P.-P. Francisca et al., "The insulin-sensitizing mechanism of myo-inositol is associated with AMPK activation and GLUT-4 expression in human endometrial cells exposed to a PCOS environment," American Journal of Physiology. Endocrinology and Metabolism, vol. 318, no. 2, 2020.

[45] Y. Zhu, L. Wang, H. C. Zhao et al., "Proteomics study of endometrium in patients with polycystic ovarian syndrome," Chinese Journal of Family Planning, vol. 28, no. 10, pp. $1526-1528+1721,2020$.

[46] Z. Haoula, M. Salman, and W. Atiomo, "Evaluating the association between endometrial cancer and polycystic ovary syndrome," Human Reproduction, vol. 27, no. 5, pp. 1327-1331, 2012.

[47] C. Avellaira, A. Villavicencio, K. Bacallao et al., "Expression of molecules associated with tissue homeostasis in secretory endometria from untreated women with polycystic ovary syndrome," Human Reproduction, vol. 21, no. 12, pp. 3116-3121, 2006.

[48] G. Q. Luo, W. F. Deng, Q. R. Liu et al., "Endometrial pathological changes and expression of insulin receptor protein in the patients with polycystic ovary syndrome," Chinese Journal of Family Planning, vol. 21, no. 1, pp. 32-35, 2013. 
[49] M. Asadi, N. Matin, M. Frootan, J. Mohamadpour, M. Qorbani, and F. D. Tanha, "Vitamin D improves endometrial thickness in PCOS women who need intrauterine insemination: a randomized double-blind placebo-controlled trial," Archives of Gynecology and Obstetrics, vol. 289, no. 4, pp. 865-870, 2014.

[50] M. Boyd and J. Ziegler, "Polycystic ovary syndrome, fertility, diet, and lifestyle modifications," Topics in Clinical Nutrition, vol. 34, no. 1, pp. 14-30, 2019.

[51] J. Jo, Y. J. Lee, and H. Lee, "Acupuncture for polycystic ovarian syndrome," Medicine, vol. 96, no. 23, p. e7066, 2017.

[52] CONSORT Statement 2001-Checklist: items to include when reporting a randomized trial.2001. http://www. consort-statement.org. 